\title{
Kinetic multi-layer model of aerosol surface and bulk chemistry (KM-SUB): the influence of interfacial transport and bulk diffusion on the oxidation of oleic acid by ozone
}

\author{
M. Shiraiwa ${ }^{1}$, C. Pfrang ${ }^{1,2}$, and U. Pöschl ${ }^{1}$ \\ ${ }^{1}$ Max Planck Institute for Chemistry, Biogeochemistry Department, P.O. Box 3060, 55128 Mainz, Germany \\ ${ }^{2}$ University of Reading, Department of Chemistry, P.O. Box 224, Whiteknights, Reading RG6 6AD, UK
}

Received: 17 December 2009 - Published in Atmos. Chem. Phys. Discuss.: 8 January 2010

Revised: 8 April 2010 - Accepted: 9 April 2010 - Published: 20 April 2010

\begin{abstract}
We present a novel kinetic multi-layer model that explicitly resolves mass transport and chemical reaction at the surface and in the bulk of aerosol particles (KM-SUB). The model is based on the PRA framework of gas-particle interactions (Pöschl-Rudich-Ammann, 2007), and it includes reversible adsorption, surface reactions and surface-bulk exchange as well as bulk diffusion and reaction. Unlike earlier models, KM-SUB does not require simplifying assumptions about steady-state conditions and radial mixing. The temporal evolution and concentration profiles of volatile and nonvolatile species at the gas-particle interface and in the particle bulk can be modeled along with surface concentrations and gas uptake coefficients.

In this study we explore and exemplify the effects of bulk diffusion on the rate of reactive gas uptake for a simple reference system, the ozonolysis of oleic acid particles, in comparison to experimental data and earlier model studies. We demonstrate how KM-SUB can be used to interpret and analyze experimental data from laboratory studies, and how the results can be extrapolated to atmospheric conditions. In particular, we show how interfacial and bulk transport, i.e., surface accommodation, bulk accommodation and bulk diffusion, influence the kinetics of the chemical reaction. Sensitivity studies suggest that in fine air particulate matter oleic acid and compounds with similar reactivity against ozone (carbon-carbon double bonds) can reach chemical lifetimes of many hours only if they are embedded in a (semi-)solid matrix with very low diffusion coefficients $\left(\leq 10^{-10} \mathrm{~cm}^{2} \mathrm{~s}^{-1}\right)$.
\end{abstract}

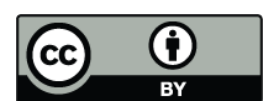

Correspondence to: U. Pöschl (u.poschl@mpic.de)
Depending on the complexity of the investigated system, unlimited numbers of volatile and non-volatile species and chemical reactions can be flexibly added and treated with KM-SUB. We propose and intend to pursue the application of KM-SUB as a basis for the development of a detailed master mechanism of aerosol chemistry as well as for the derivation of simplified but realistic parameterizations for largescale atmospheric and climate models.

\section{Introduction}

Aerosols are ubiquitous in the atmosphere and have strong effects on climate and public health (Seinfeld and Pandis, 1998; Finlayson-Pitts and Pitts, 2000; Pöschl, 2005). Depending on chemical composition and surface properties, aerosol particles can act as condensation nuclei for cloud droplets and ice crystals, and they can affect the abundance of trace gases through heterogeneous chemical reactions (Ammann et al., 1998; Pöschl, 2005; Fuzzi et al., 2006; Andreae and Rosenfeld, 2008; Hallquist et al., 2009). Gasparticle interactions can also significantly change the physical and chemical properties of aerosols such as toxicity, reactivity, hygroscopicity and radiative properties (Pöschl, 2002; Rudich, 2003; Kanakidou et al., 2005; Rincon et al., 2009; Wiedensohler et al., 2009). Chemical reactions and mass transport lead to continuous transformation and changes in the composition of atmospheric aerosols ("chemical aging") (Schwartz and Freiberg, 1981; Hanson, 1997; Smith et al., 2003; Ammann and Pöschl, 2007).

Atmospheric particles consist of a wide variety of organic and inorganic chemical compounds which can exist in different liquid or (semi-)solid states (crystalline, amorphous,

Published by Copernicus Publications on behalf of the European Geosciences Union. 
glassy, ultraviscous, gel-like) (Seinfeld and Pandis, 1998; Finlayson-Pitts and Pitts, 2000; Mikhailov et al., 2009). Chemical reactions can occur both at the surface and in the bulk of liquid and (semi-)solid particles. It is often difficult to discriminate surface and bulk reactions, and the relative importance of surface and bulk processes is not well understood (e.g., Moise and Rudich, 2000; Hearn et al., 2005; Pfrang et al., 2009). Resistor model formulations are widely used to describe and investigate heterogeneous reactions and multiphase processes in laboratory, field and model studies of atmospheric chemistry (Hanson, 1997; Finlayson-Pitts and Pitts, 2000; Worsnop et al., 2002; Anttila et al., 2006; King et al., 2008, 2009; and references therein). The traditional resistor models, however, are usually based on simplifying assumptions such as steady-state conditions, homogeneous mixing, and limited numbers of non-interacting species and processes.

In order to overcome these limitations, Pöschl, Rudich and Ammann have developed a kinetic model framework (PRA framework) with a double-layer surface concept and universally applicable rate equations and parameters for mass transport and chemical reactions at the gas-particle interface of aerosols and clouds (Pöschl et al., 2007). Ammann and Pöschl (2007) provided first examples on how the PRA framework can be applied to describe various physicochemical processes in aerosols and clouds such as reactive gas uptake on solid particles and solubility saturation of liquid droplets under transient or steady-state conditions. Springmann et al. (2009) demonstrated the applicability and usefulness of the PRA framework in an urban plume box model of the degradation of benzo[a]pyrene on soot by ozone and nitrogen dioxide. Shiraiwa et al. (2009) presented a kinetic double-layer surface model (K2-SURF) and master mechanism for the degradation of a wide range of polycyclic aromatic hydrocarbons (PAHs) by multiple photo-oxidants $\left(\mathrm{O}_{3}, \mathrm{NO}_{2}, \mathrm{OH}\right.$ and $\left.\mathrm{NO}_{3}\right)$ through different types of parallel and sequential surface reactions. Pfrang et al. (2009) developed a kinetic double-layer model coupling aerosol surface and bulk chemistry (K2-SUB), in which mass transport and chemical reactions in the particle are not explicitly resolved but represented by a reacto-diffusive flux (Danckwerts, 1951; Hanson, 1997).

Here we present a kinetic multi-layer model of aerosol surface and bulk chemistry (KM-SUB) that explicitly treats all steps of mass transport and chemical reaction from the gas-particle interface to the particle core, resolving concentration gradients and diffusion throughout the particle bulk. We demonstrate the applicability of KM-SUB for a common model system of organic aerosol chemistry, the ozonolysis of oleic acid droplets (e.g., Moise and Rudich, 2002; Katrib et al., 2004, 2005; King et al., 2004, 2009; Knopf et al., 2005; Ziemann, 2005; Hearn and Smith, 2007; Pfrang et al., 2009; Sage et al., 2009; Vesna et al., 2009), and we compare the results of our numerical simulations with the results of earlier experimental and theoretical studies of this system.

\section{Model description}

The kinetic multi-layer model of aerosol surface and bulk chemistry (KM-SUB) builds on the formalism and terminology of the PRA framework (Ammann and Pöschl, 2007; Pöschl et al., 2007). A list of symbols is given in Appendix A.

As illustrated in Fig. 1, KM-SUB consists of multiple model compartments and layers, respectively: gas phase, near-surface gas phase, sorption layer, quasi-static surface layer, near-surface bulk, and a number of $n$ bulk layers. The quasi-static surface layer has a monolayer thickness that corresponds to the (average) effective molecular diameter of non-volatile species $\mathrm{Y}_{j}\left(\delta_{\mathrm{Y}_{j}}\right)$. The thickness of bulk layers $(\delta)$ follows from the number of layers $(n)$ and particle radius $\left(r_{\mathrm{p}}\right): \delta=\left(r_{\mathrm{p}}-\delta_{\mathrm{Y}_{j}}\right) / n$.

The following processes are considered in KM-SUB: gas phase diffusion, gas-surface transport (reversible adsorption), surface layer reactions, surface-bulk transport, bulk diffusion, and bulk reactions. As outlined in the PRA framework, the following differential equations can be used to describe the mass balance of volatile species $X_{i}$ and nonvolatile species $\mathrm{Y}_{j}$ for each model layer:

$$
\begin{aligned}
& \mathrm{d}\left[\mathrm{X}_{i}\right]_{\mathrm{s}} / \mathrm{d} t=J_{\mathrm{ads}, \mathrm{X}_{i}}-J_{\mathrm{des}, \mathrm{X}_{i}}+P_{\mathrm{s}, \mathrm{X}_{i}}-L_{\mathrm{s}, \mathrm{X}_{i}} \\
& -J_{\mathrm{s}, \mathrm{b}, \mathrm{X}_{i}}+J_{\mathrm{b}, \mathrm{s}, \mathrm{X}_{i}} \\
& \mathrm{~d}\left[\mathrm{Y}_{j}\right]_{\mathrm{ss}} / \mathrm{d} t=J_{\mathrm{b}, \mathrm{ss}, \mathrm{Y}_{j}}-J_{\mathrm{ss}, \mathrm{b}, \mathrm{Y}_{j}}+P_{\mathrm{ss}, \mathrm{Y}_{j}}-L_{\mathrm{ss}, \mathrm{Y}_{j}} \\
& \mathrm{~d}\left[\mathrm{X}_{i}\right]_{\mathrm{b} 1} / \mathrm{d} t=\left(J_{\mathrm{s}, \mathrm{b}, \mathrm{X}_{i}}-J_{\mathrm{b}, \mathrm{s}, \mathrm{X}_{i}}\right) A(1) / V(1) \\
& -\left(J_{\mathrm{b} 1, \mathrm{~b} 2, \mathrm{X}_{i}}-J_{\mathrm{b} 2, \mathrm{~b} 1, \mathrm{X}_{i}}\right) A(2) / V(1)+P_{\mathrm{b} 1, \mathrm{X}_{i}}-L_{\mathrm{b} 1, \mathrm{X}_{i}}
\end{aligned}
$$

$$
\begin{aligned}
& \mathrm{d}\left[\mathrm{Y}_{j}\right]_{\mathrm{b} 1} / \mathrm{d} t=\left(J_{\mathrm{ss}, \mathrm{b}, \mathrm{Y}_{j}}-J_{\mathrm{b}, \mathrm{ss}, \mathrm{Y}_{j}}\right) A(1) / V(1) \\
& -\left(J_{\mathrm{b} 1, \mathrm{~b} 2, \mathrm{Y}_{j}}-J_{\mathrm{b} 2, \mathrm{~b} 1, \mathrm{Y}_{j}}\right) A(2) / V(1)+P_{\mathrm{b} 1, \mathrm{Y}_{j}}-L_{\mathrm{b} 1, \mathrm{Y}_{j}}
\end{aligned}
$$

$$
\begin{aligned}
& \mathrm{d}\left[\mathrm{X}_{i}\right]_{\mathrm{b} k} / \mathrm{d} t=\left(J_{\mathrm{b} k-1, \mathrm{~b} k, \mathrm{X}_{i}}-J_{\mathrm{b} k, \mathrm{~b} k-1, \mathrm{X}_{i}}\right) A(k) / V(k) \\
& -\left(J_{\mathrm{b} k, \mathrm{~b} k+1, \mathrm{X}_{i}}-J_{\mathrm{b} k+1, \mathrm{~b} k, \mathrm{X}_{i}}\right) A(k+1) / V(k)+P_{\mathrm{b} k, \mathrm{X}_{i}} \\
& -L_{\mathrm{b} k, \mathrm{X}_{i}} \quad(k=2, \ldots, n-1)
\end{aligned}
$$

$$
\begin{aligned}
& \mathrm{d}\left[\mathrm{Y}_{j}\right]_{\mathrm{b} k} / \mathrm{d} t=\left(J_{\mathrm{b} k-1, \mathrm{~b} k, \mathrm{Y}_{j}}-J_{\mathrm{b} k, \mathrm{~b} k-1, \mathrm{Y}_{j}}\right) A(k) / V(k) \\
& -\left(J_{\mathrm{b} k, \mathrm{~b} k+1, \mathrm{Y}_{j}}-J_{\mathrm{b} k+1, \mathrm{~b} k, \mathrm{Y}_{j}}\right) A(k+1) / V(k)+P_{\mathrm{b} k, \mathrm{Y}_{j}} \\
& -L_{\mathrm{b} k, \mathrm{Y}_{j}} \quad(k=2, \ldots, n-1)
\end{aligned}
$$

$$
\begin{aligned}
& \mathrm{d}\left[\mathrm{X}_{i}\right]_{\mathrm{b} n} / \mathrm{d} t=\left(J_{\mathrm{b} n-1, \mathrm{~b} n, \mathrm{X}_{i}}-J_{\mathrm{b} n, \mathrm{~b} n-1, \mathrm{X}_{i}}\right) A(n) / V(n) \\
& +P_{\mathrm{b} n, \mathrm{X}_{i}}-L_{\mathrm{b} n, \mathrm{X}_{i}}
\end{aligned}
$$



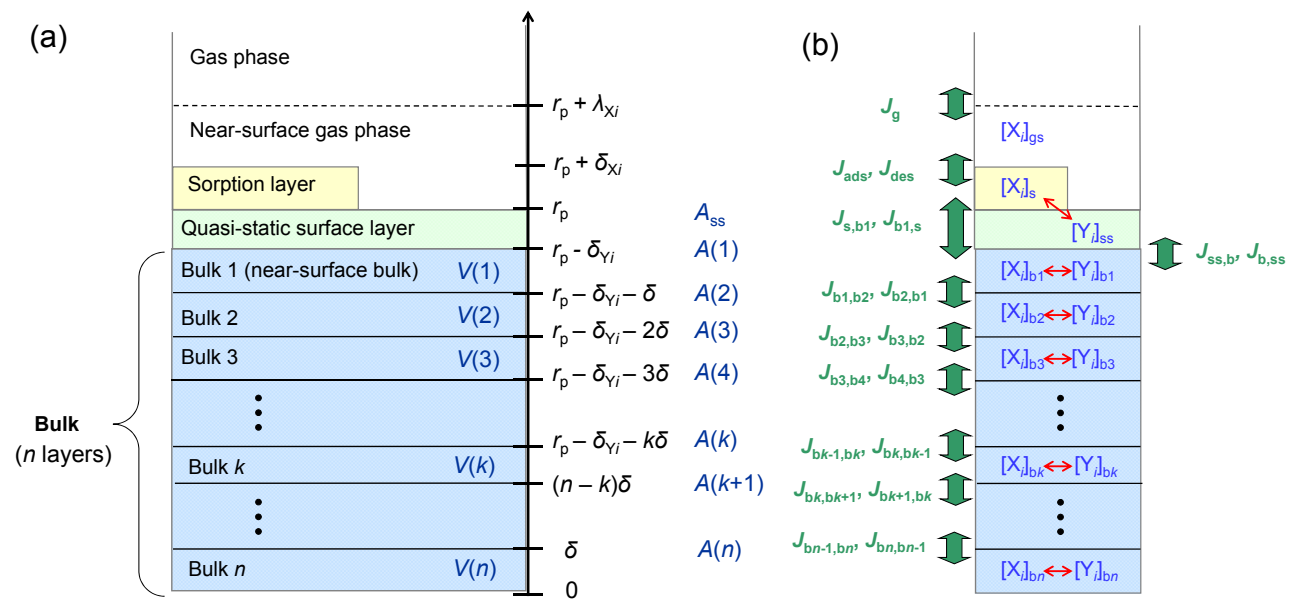

Fig. 1. Kinetic multi-layer model (KM-SUB): (a) Model compartments and layers with corresponding distances from particle center $\left(r_{\mathrm{p}} \pm\right.$ $x)$, surface areas $(A)$ and volumes $(V) ; \lambda \mathrm{X}_{i}$ is the mean free path of $\mathrm{X}_{i}$ in the gas phase; $\delta_{\mathrm{X}_{i}}$ and $\delta_{\mathrm{Y}_{j}}$ are the thicknesses of sorption and quasi-static bulk layers; $\delta$ is the bulk layer thickness. (b) Transport fluxes (green arrows) and chemical reactions (red arrows).

$$
\begin{aligned}
& \mathrm{d}\left[\mathrm{Y}_{j}\right]_{\mathrm{b} n} / \mathrm{d} t=\left(J_{\mathrm{b} n-1, \mathrm{~b} n, \mathrm{Y}_{j}}-J_{\mathrm{b} n, \mathrm{~b} n-1, \mathrm{Y}_{j}}\right) A(n) / V(n) \\
& +P_{\mathrm{b} n, \mathrm{Y}_{j}}-L_{\mathrm{b} n, \mathrm{Y}_{j}}
\end{aligned}
$$

The various types of mass transport fluxes $(J)$ and rates of chemical production and loss $(P, L)$ are defined in the list of symbols (Table A1). $A(k)$ and $V(k)$ are the outer surface area and the volume of the bulk layer $k$, respectively (Fig. 1). For spherical particles, $A(k)$ and $V(k)$ can be calculated from the particle bulk radius $\left(r_{\mathrm{b}}=r_{\mathrm{p}}-\delta_{\mathrm{Y}_{j}}\right)$, bulk layer thickness $(\delta)$ and layer index number $k$ as follows.

$$
\begin{aligned}
& V(k)=\frac{4}{3} \pi\left[\left(r_{\mathrm{b}}-(k-1) \delta\right)^{3}-\left(r_{\mathrm{b}}-k \delta\right)^{3}\right] \\
& A(k)=4 \pi\left(r_{\mathrm{b}}-(k-1) \delta\right)^{2}
\end{aligned}
$$

For planar geometry (thin films), the surface-to-volume ratio is constant:

$$
A(k) / V(k)=1 / \delta
$$

The surface-to-volume ratios of the layers play an important role in accounting for particle geometry. The absolute number of non-volatile molecules $\mathrm{Y}_{j}$ in the particle $\left(N_{\mathrm{Y}_{j}}\right)$ can be calculated as follows:

$N_{\mathrm{Y}_{j}}=\left[\mathrm{Y}_{j}\right]_{\mathrm{ss}} A_{\mathrm{ss}}+\sum_{k=1}^{n}\left[\mathrm{Y}_{j}\right]_{\mathrm{b} k} V(k)$

where $A_{\mathrm{ss}}$ is the surface area of the particle. In the following sub-sections we specify the formalisms used to describe and calculate fluxes or rates of gas-surface interactions, surfacebulk transport, bulk diffusion and bulk reactions.

\subsection{Gas-surface interactions and surface layer reactions}

The principles and details of gas-phase and gas-surface transport $\left(J_{\mathrm{ads}}, J_{\mathrm{des}}\right)$ and surface layer reactions $\left(L_{\mathrm{s}}, L_{\mathrm{ss}} P_{\mathrm{s}}, P_{\mathrm{ss}}\right)$ have been discussed and illustrated in the PRA framework (Pöschl et al., 2007; Ammann and Pöschl, 2007) and in the K2-SURF study of aerosol surface chemistry (Shiraiwa et al., 2009). Here we just briefly summarize the key aspects and equations. The fluxes of surface collisions, adsorption and desorption of a volatile species $\mathrm{X}_{i}\left(J_{\mathrm{coll}, \mathrm{X}_{i}}, J_{\mathrm{ads}, \mathrm{X}_{i}}\right.$ and $J_{\text {des, }, X_{i}}$ ) are given by:

$J_{\mathrm{coll}, \mathrm{X}_{i}}=\left[\mathrm{X}_{i}\right]_{\mathrm{gs}} \omega_{\mathrm{X}_{i}} / 4$

$J_{\mathrm{ads}, \mathrm{X}_{i}}=\alpha_{\mathrm{s}, \mathrm{X}_{i}} J_{\mathrm{coll}, \mathrm{X}_{i}}$

$J_{\mathrm{des}, \mathrm{X}_{i}}=k_{\mathrm{d}, \mathrm{X}_{i}}\left[\mathrm{X}_{i}\right]_{\mathrm{s}}$

$\alpha_{\mathrm{s}, \mathrm{X}_{i}}=\alpha_{\mathrm{s}, 0, \mathrm{X}_{i}}\left(1-\theta_{\mathrm{s}}\right)$

$\theta_{\mathrm{s}}=\sum_{i} \sigma_{\mathrm{s}, \mathrm{X}_{i}}\left[\mathrm{X}_{i}\right]_{\mathrm{s}}$

$\left[\mathrm{X}_{i}\right]_{\mathrm{gs}}$ is the near-surface gas phase concentration of $\mathrm{X}_{i}, \omega_{\mathrm{X}_{i}}$ is the mean thermal velocity, $\alpha_{\mathrm{s}, \mathrm{X}_{i}}$ is the surface accommodation coefficient, and $k_{\mathrm{d}, X_{i}}$ is the desorption rate coefficient or inverse desorption lifetime, respectively $\left(k_{\mathrm{d}, \mathrm{X}_{i}}=\right.$ $\left.\tau_{\mathrm{d}, \mathrm{X}_{i}}^{-1}\right) \cdot \alpha_{\mathrm{s}, 0, \mathrm{X}_{i}}$ is the surface accommodation coefficient on an adsorbate-free surface, $\sigma_{\mathrm{s}, \mathrm{X}_{i}}$ is the effective molecular cross section of $\mathrm{X}_{i}$ in the sorption layer, and $\theta_{\mathrm{S}}$ is the surface coverage by adsorbed species.

The influence of changing chemical composition of the quasi-static particle surface on adsorbate-surface interactions (reversible adsorption) can be taken into account by describing $\alpha_{\mathrm{s}, 0, \mathrm{X}_{i}}$ and $\tau_{\mathrm{d}, \mathrm{X}_{i}}$ as a linear combination of the parameter values $\alpha_{\mathrm{s}, 0, \mathrm{X}_{i}, \mathrm{Y}_{j}}$ and $\tau_{\mathrm{d}, \mathrm{X}_{i}, \mathrm{Y}_{j}}$ that would be observed on pure 
substrates made up by the different surface components $\mathrm{Y}_{j}$ weighted by their fractional surface area $\theta_{\mathrm{ss}, Y_{j}}$ (Pöschl et al., 2007):

$\alpha_{\mathrm{s}, 0, \mathrm{X}_{i}}=\sum_{j} \alpha_{\mathrm{s}, 0, \mathrm{X}_{i}, \mathrm{Y}_{j}} \theta_{\mathrm{ss}, \mathrm{Y}_{j}}$

$\tau_{\mathrm{d}, \mathrm{X}_{i}}=\sum_{j} \tau_{\mathrm{d}, \mathrm{X}_{i}, \mathrm{Y}_{j}} \theta_{\mathrm{ss}, \mathrm{Y}_{j}}$

For slow gas uptake and in the gas kinetic-regime (small uptake coefficient, large Knudsen number), $\left[\mathrm{X}_{i}\right]_{\mathrm{gs}}$ is practically the same as the average gas phase concentration of $\mathrm{X}_{i}$ in the investigated system, $\left[\mathrm{X}_{i}\right]_{\mathrm{g}}$. For rapid gas uptake in the continuum or transition regime (large uptake coefficient, small Knudsen number), the gas phase diffusion correction factor $C_{\mathrm{g}, \mathrm{X}_{i}}$ can be used to calculate $\left[\mathrm{X}_{i}\right]_{\mathrm{gs}}$ from $\left[\mathrm{X}_{i}\right]_{\mathrm{g}}:\left[\mathrm{X}_{i}\right]_{\mathrm{gs}}=C_{\mathrm{g}, \mathrm{X}_{i}}\left[\mathrm{X}_{i}\right]_{\mathrm{g}}$ (Pöschl et al., 2007; Shiraiwa et al., 2009). The uptake coefficient $\left(\gamma_{X_{i}}\right)$ for $X_{i}$ is given by:

$\gamma_{\mathrm{X}_{i}}=\frac{J_{\mathrm{ads}, \mathrm{X}_{i}}-J_{\mathrm{des}, \mathrm{X}_{i}}}{J_{\mathrm{coll}, \mathrm{X}_{i}}}+\gamma_{\mathrm{gsr}, \mathrm{X}_{i}}$

$\gamma_{\mathrm{gsr}, \mathrm{X}_{i}}$ is the reaction probability for elementary gas-surface reactions (potentially relevant for free radicals but assumed to be zero in the remainder of this study).

General rate equations of chemical production and loss by surface layer reactions $\left(P_{\mathrm{s}, \mathrm{X}_{i}}, P_{\mathrm{ss}, \mathrm{Y}_{i}}, L_{\mathrm{s}, \mathrm{X}_{i}}, L_{\mathrm{ss}, \mathrm{Y}_{i}}\right)$ are specified in the PRA framework (Sect. 3.3, Pöschl et al., 2007). Different types of surface layer reactions can proceed within the sorption layer $\left(P_{\mathrm{s}, \mathrm{s}, \mathrm{X}_{i}}-L_{\mathrm{s}, \mathrm{s}, \mathrm{X}_{i}}\right)$, within the quasi-static surface layer $\left(P_{\mathrm{ss}, \mathrm{ss}, \mathrm{Y}_{j}}-L_{\mathrm{ss}, \mathrm{ss}, \mathrm{Y}_{j}}\right)$, and between sorption layer and quasi-static layer $\left(P_{\mathrm{s}, \mathrm{ss}, \mathrm{X}_{i}}-L_{\mathrm{s}, \mathrm{ss}, \mathrm{X}_{i}}\right.$, $\left.P_{\mathrm{ss}, \mathrm{s}, \mathrm{Y}_{j}}-L_{\mathrm{ss}, \mathrm{s}, \mathrm{Y}_{j}}\right)$. The generalized rate equations for reactions between volatile species $X_{i}$ in the sorption layer and non-volatile species $\mathrm{Y}_{j}$ in the quasi-static layer are given by:

$P_{\mathrm{s}, \mathrm{ss}, \mathrm{X}_{i}}-L_{\mathrm{s}, \mathrm{ss}, \mathrm{X}_{i}}$

$=\sum_{v} \sum_{p} \sum_{q} c_{\mathrm{SLR} v, \mathrm{~s}, \mathrm{X}_{i}} k_{\mathrm{SLR} v, \mathrm{X}_{p}, \mathrm{Y}_{q}}\left[\mathrm{X}_{p}\right]_{\mathrm{s}}\left[\mathrm{Y}_{q}\right]_{\mathrm{ss}}$

$P_{\mathrm{ss}, \mathrm{ss}, \mathrm{Y}_{j}}-L_{\mathrm{ss}, \mathrm{ss}, \mathrm{Y}_{j}}$

$=\sum_{v} \sum_{p} \sum_{q} c_{\mathrm{SLR} v, \mathrm{ss}, \mathrm{Y}_{j}} k_{\mathrm{SLR} v, \mathrm{X}_{p}, \mathrm{Y}_{q}}\left[\mathrm{X}_{p}\right]_{\mathrm{s}}\left[\mathrm{Y}_{q}\right]_{\mathrm{ss}}$

Here $c_{\mathrm{SLR} v, \mathrm{~s}, \mathrm{X}_{i}}$ and $c_{\mathrm{SLR} v, \mathrm{ss}, \mathrm{Y}_{j}}$ stand for the stoichiometric coefficients (negative for starting materials and positive for reaction products) of species $\mathrm{X}_{i}$ and $\mathrm{Y}_{j}$ in reaction $\operatorname{SLR} v$; $v=1, \ldots, v_{\max }$ in a system with a total number of $v_{\max }$ (photo-)chemical reactions occurring on the surface of the

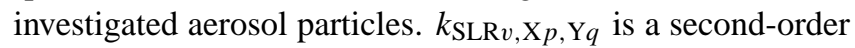
reaction rate coefficient. In the exemplary simulations of the ozonolysis of oleic acid performed in this study and presented in Sect. 3, we consider only chemical loss and a second-order surface layer reaction between $\mathrm{O}_{3}(\mathrm{X})$ and oleic acid $(\mathrm{Y})$ with the following rate equation:

$L_{\mathrm{s}, \mathrm{X}}=L_{\mathrm{ss}, \mathrm{Y}}=k_{\mathrm{SLR}, \mathrm{X}, \mathrm{Y}}[\mathrm{X}]_{\mathrm{s}}[\mathrm{Y}]_{\mathrm{ss}}$

\subsection{Surface-bulk transport}

The surface-bulk transport of volatile species $\mathrm{X}_{i}\left(J_{\mathrm{s}, \mathrm{b}, \mathrm{X}_{i}}\right.$ and $\left.J_{\mathrm{b}, \mathrm{s}, \mathrm{X}_{i}}\right)$ is defined as exchange between sorption layer and near-surface bulk, and the surface-bulk transport of nonvolatile species $\mathrm{Y}_{j}\left(J_{\mathrm{ss}, \mathrm{b}, \mathrm{Y}_{j}}\right.$ and $\left.J_{\mathrm{b}, \mathrm{ss}, \mathrm{Y}_{j}}\right)$ is defined as exchange between quasi-static surface layer and near-surface bulk. Based on the PRA framework, surface to bulk transport can be described by:

$J_{\mathrm{s}, \mathrm{b}, \mathrm{X}_{i}}=k_{\mathrm{s}, \mathrm{b}, \mathrm{X}_{i}}\left[\mathrm{X}_{i}\right]_{\mathrm{s}}$

$J_{\mathrm{ss}, \mathrm{b}, \mathrm{Y}_{j}}=k_{\mathrm{ss}, \mathrm{b}, \mathrm{Y}_{j}}\left[\mathrm{Y}_{j}\right]_{\mathrm{ss}}$

$k_{\mathrm{s}, \mathrm{b}, \mathrm{X}_{i}}$ and $k_{\mathrm{ss}, \mathrm{b}, \mathrm{Y}_{j}}$ are first-order transport rate coefficients $\left(\mathrm{s}^{-1}\right)$ of $\mathrm{X}_{i}$ and $\mathrm{Y}_{j}$, respectively. In the same way, bulk to surface transport $\left(J_{\mathrm{b}, \mathrm{s}, \mathrm{X}_{i}}\right.$ and $\left.J_{\mathrm{b}, \mathrm{ss}, \mathrm{Y}_{j}}\right)$ can be described as follows:

$J_{\mathrm{b}, \mathrm{s}, \mathrm{X}_{i}}=k_{\mathrm{b}, \mathrm{s}, \mathrm{X}_{i}}\left[\mathrm{X}_{i}\right]_{\mathrm{b} 1}$

$J_{\mathrm{b}, \mathrm{ss}, \mathrm{Y}_{j}}=k_{\mathrm{b}, \mathrm{ss}, \mathrm{Y}_{j}}\left[\mathrm{Y}_{j}\right]_{\mathrm{b} 1}$

$k_{\mathrm{b}, \mathrm{s}, \mathrm{X}_{i}}$ and $k_{\mathrm{b}, \mathrm{ss}, \mathrm{Y}_{j}}\left(\mathrm{~cm} \mathrm{~s}^{-1}\right)$ are transport rate coefficients, which can be regarded as effective transport velocities. Estimates for these effective transport velocities can be derived from the corresponding bulk diffusion coefficients $D_{\mathrm{b}, \mathrm{X}_{i}}$ and $D_{\mathrm{b}, \mathrm{Y}_{j}}\left(\mathrm{~cm}^{2} \mathrm{~s}^{-1}\right)$ by considering the average distance traveled by molecules diffusing in one direction: $x=\left(4 D_{\mathrm{b}} t / \pi\right)^{1 / 2}$ (Atkins, 1998; Pfrang et al., 2009), On average, a molecule $\mathrm{Y}_{j}$ in the near-surface bulk layer $(k=1)$ needs to travel a distance of $x \approx\left(\delta+\delta_{\mathrm{Y}_{j}}\right) / 2$ to move into the quasi-static surface layer. The average time required to travel over this distance by diffusion is $t=\left(\delta+\delta_{\mathrm{Y}_{j}}\right)^{2} \pi /\left(16 D_{\mathrm{b}, \mathrm{Y}_{j}}\right)$. By division of travel distance over travel time we obtain the following estimate for the effective transport velocity:

$k_{\mathrm{b}, \mathrm{ss}, \mathrm{Y}_{j}} \approx 8 D_{\mathrm{b}, \mathrm{Y}_{j}} /\left(\left(\delta+\delta_{\mathrm{Y}_{j}}\right) \pi\right)$

Under equilibrium conditions, mass conservation implies $k_{\mathrm{b}, \mathrm{ss}, \mathrm{Y}_{j}}\left[\mathrm{Y}_{j}\right]_{\mathrm{b} 1}=k_{\mathrm{ss}, \mathrm{b}, \mathrm{Y}_{j}}\left[\mathrm{Y}_{j}\right]_{\mathrm{ss}}$, and for pure $\mathrm{Y}_{j}$ the surface and bulk concentrations are given by the inverse of the effective molecular cross section and of the effective molecular volume, respectively: $\left[\mathrm{Y}_{j}\right]_{\mathrm{ss}}=\delta_{\mathrm{Y}_{j}}^{-2}$ and $\left[\mathrm{Y}_{j}\right]_{\mathrm{b} 1}=\delta_{\mathrm{Y}_{j}}^{-3}$. Thus, we obtain

$k_{\mathrm{ss}, \mathrm{b}, \mathrm{Y}_{j}} \approx k_{\mathrm{b}, \mathrm{ss}, \mathrm{Y}_{j}} / \delta_{\mathrm{Y}_{j}} \approx 8 D_{\mathrm{b}, \mathrm{Y}_{j}} /\left(\left(\delta+\delta_{\mathrm{Y}_{j}}\right) \delta_{\mathrm{Y}_{j}} \pi\right)$

In analogy, the bulk-to-surface transport velocity of $\mathrm{X}_{i}$ can be calculated for an average travel distance of $x \approx$ $\left(\delta+\delta \mathrm{X}_{i}+2 \delta_{\mathrm{Y}_{j}}\right) / 2$ from the near-surface bulk layer into the sorption layer:

$k_{\mathrm{b}, \mathrm{s}, \mathrm{X}_{i}} \approx 8 D_{\mathrm{b}, \mathrm{X}_{i}} /\left(\left(\delta+\delta_{\mathrm{X}_{i}}+2 \delta_{\mathrm{Y}_{j}}\right) \pi\right)$

An estimate for $k_{\mathrm{s}, \mathrm{b}, \mathrm{X}_{i}}$ can be determined by matching the rate coefficients for gas-surface and surface-bulk transport 
with a literature value or estimate for the gas-particle equilibrium partitioning coefficient $\left(K_{\mathrm{sol}, \mathrm{cc}, \mathrm{X}_{i}}\right)$ or Henry's law coefficient, respectively (Pöschl et al., 2007):

$k_{\mathrm{s}, \mathrm{b}, \mathrm{X}_{i}}=\frac{4 k_{\mathrm{b}, \mathrm{s}, \mathrm{X}_{i}} K_{\mathrm{sol}, \mathrm{cc}, \mathrm{X}_{i}} k_{\mathrm{d}, \mathrm{X}_{i}}}{\alpha_{\mathrm{s}, \mathrm{X}_{i}} \omega_{\mathrm{X}_{i}}}$

where $k_{\mathrm{d}, \mathrm{X}_{i}}$ is the first-order rate coefficient of desorption. From the fluxes and rates of gas-surface transport, surfacebulk transport and surface reaction follows the bulk accomodation coefficient of $X_{i}$ :

$\alpha_{\mathrm{b}, \mathrm{X}_{i}}=\alpha_{\mathrm{s}, \mathrm{X}_{i}} \frac{J_{\mathrm{s}, \mathrm{b}, \mathrm{X}_{i}}}{J_{\mathrm{des}, \mathrm{X}_{i}}+J_{\mathrm{s}, \mathrm{b}, \mathrm{X}_{i}}+L_{\mathrm{s}, \mathrm{X}_{i}}}$

\subsection{Bulk diffusion}

Bulk diffusion is explicitly treated in the KM-SUB model as the mass transport $\left(J_{\mathrm{b} k, \mathrm{~b} k \pm 1}\right)$ from one bulk layer (bulk $k$ ) to the next (bulk $k \pm 1$ ). In analogy to surface-bulk mass transport, we describe the mass transport fluxes between different layers of the bulk by first-order rate equations:

$$
\begin{aligned}
J_{\mathrm{b} k, \mathrm{~b} k \pm 1, \mathrm{X}_{i}} & =k_{\mathrm{b}, \mathrm{b}, \mathrm{X}_{i}}\left[\mathrm{X}_{i}\right]_{\mathrm{b} k} \\
J_{\mathrm{b} k, \mathrm{~b} k \pm 1, \mathrm{Y}_{j}} & =k_{\mathrm{b}, \mathrm{b}, \mathrm{Y}_{j}}\left[\mathrm{Y}_{j}\right]_{\mathrm{b} k}
\end{aligned}
$$

Estimates for the transport rate coefficients or effective velocities of $\mathrm{X}_{i}$ and $\mathrm{Y}_{j}, k_{\mathrm{b}, \mathrm{b}, \mathrm{X}_{i}}$ and $k_{\mathrm{b}, \mathrm{b}, \mathrm{Y}_{j}}\left(\mathrm{~cm} \mathrm{~s}^{-1}\right)$, can be calculated from the corresponding diffusion coefficients. For this purpose we assume that each layer is homogeneously mixed (no concentration gradient within a layer) and that the average travel distance for molecules moving from one layer to the next is the layer thickness $\delta$ :

$k_{\mathrm{b}, \mathrm{b}, \mathrm{X}_{i}}=4 D_{\mathrm{b}, \mathrm{X}_{i}} /(\pi \delta)$
$k_{\mathrm{b}, \mathrm{b}, \mathrm{Y}_{j}}=4 D_{\mathrm{b}, \mathrm{Y}_{j}} /(\pi \delta)$

This treatment of bulk diffusion yields practically the same results (concentration profiles) as the solving of partial differential equations (Smith et al., 2003), but it is more flexible and requires no assumptions about interfacial transport. As detailed in Appendix B, the ozone concentrations calculated for the near-surface bulk indicate that the assumption of Henry's law equilibrium is not a realistic boundary layer condition for the PDE method when applied to reactive systems.

The influence of changing chemical composition of the particle bulk on diffusion can be taken into account by describing $D_{\mathrm{b}, \mathrm{X}_{i}}$ or $D_{\mathrm{b}, \mathrm{Y}_{j}}$ as a linear combination of the parameter values that would be observed in pure bulk $\mathrm{Y}_{p}$ :

$$
\begin{aligned}
& D_{\mathrm{b}, \mathrm{X}_{i}}=\sum_{p} D_{\mathrm{b}, \mathrm{X}_{i}, \mathrm{Y}_{p}} \Phi_{\mathrm{b}, \mathrm{Y}_{p}} \\
& D_{\mathrm{b}, \mathrm{Y}_{j}}=\sum_{p} D_{\mathrm{b}, \mathrm{Y}_{j}, \mathrm{Y}_{p}} \Phi_{\mathrm{b}, \mathrm{Y}_{p}}
\end{aligned}
$$

The weighting factor $\Phi_{\mathrm{b}, \mathrm{Y}_{p}}$ could be the mole, mass, or volume fraction of $Y_{p}$ in the bulk (Pöschl et al., 2007).

\subsection{Bulk reaction}

Chemical reactions proceeding within the bulk of a particle are defined as bulk reactions (BR). For simplicity, we assume that all relevant bulk reactions proceed via quasi-elementary steps with straightforward first- or second-order rate dependences on the concentrations within each bulk layer. The following generalized expressions can be used to describe net chemical production (i.e. production minus loss) of bulk species $\mathrm{X}_{i}$ or $\mathrm{Y}_{j}$ within the bulk layer $k$.

$$
\begin{aligned}
& P_{\mathrm{b} k, \mathrm{X}_{i}}-L_{\mathrm{b} k, \mathrm{X}_{i}}=\sum_{v} \sum_{p} c_{\mathrm{BR} v, \mathrm{X}_{i}}\left[\mathrm{X}_{p}\right]_{\mathrm{b} k} \\
& \left(k_{\mathrm{BR} v, \mathrm{X}_{p}}+\sum_{q} k_{\mathrm{BR} v, \mathrm{X}_{p}, \mathrm{X}_{q}}\left[\mathrm{X}_{q}\right]_{\mathrm{b} k}+\sum_{r} k_{\mathrm{BR} v, \mathrm{X}_{p}, \mathrm{Y}_{r}}\left[\mathrm{Y}_{r}\right]_{\mathrm{b} k}\right) \\
& P_{\mathrm{b} k, \mathrm{Y}_{j}}-L_{\mathrm{b} k, \mathrm{Y}_{j}}=\sum_{v} \sum_{p} c_{\mathrm{BR} v, \mathrm{Y}_{j}}\left[\mathrm{Y}_{p}\right]_{\mathrm{b} k} \\
& \left(k_{\mathrm{BR} v, \mathrm{Y}_{p}}+\sum_{q} k_{\mathrm{BR} v, \mathrm{Y}_{p}, \mathrm{Y}_{q}}\left[\mathrm{Y}_{q}\right]_{\mathrm{b} k}+\sum_{r} k_{\mathrm{BR} v, \mathrm{X}_{r}, \mathrm{Y}_{p}}\left[\mathrm{X}_{r}\right]_{\mathrm{b} k}\right)
\end{aligned}
$$

Here $c_{\mathrm{BR} v, \mathrm{X}_{i}}$ and $c_{\mathrm{BR} v, \mathrm{Y}_{j}}$ stand for the stoichiometric coefficients (negative for starting materials and positive for reaction products) of species $\mathrm{X}_{i}$ and $\mathrm{Y}_{j}$ in reaction $\mathrm{BR} v ; v=1$, $\ldots, v_{\max }$ in a system with a total number of $v_{\max }$ chemical reactions occurring in the bulk layer $k . k_{\mathrm{BR} v, \mathrm{X} p}$ and $k_{\mathrm{BR} v, \mathrm{Y} p}$ are first-order reaction rate coefficients and $k_{\mathrm{BR} v}, \mathrm{X} p, \mathrm{X} q$, $k_{\mathrm{BR} v, \mathrm{X} p, \mathrm{Y} r}, k_{\mathrm{BR} v, \mathrm{Y} p, \mathrm{Y} q}$ and $k_{\mathrm{BR} v, \mathrm{X} r, \mathrm{Y} p}$ are second-order bulk reaction rate coefficients between $\mathrm{X}_{p}$ and $\mathrm{X}_{q}, \mathrm{X}_{p}$ and $\mathrm{Y}_{r}$, $\mathrm{Y}_{p}$ and $\mathrm{Y}_{q}$, and $\mathrm{X}_{r}$ and $\mathrm{Y}_{p}$ respectively, in the condensed phase bulk of a system with multiple volatile species which can react with each other. In principle, higher-order reactions might also occur in real systems and could be flexibly included in the model. In the exemplary simulations of the ozonolysis of oleic acid performed in this study and presented in Sect. 3, we consider only chemical loss and a second-order bulk reaction between $\mathrm{O}_{3}(\mathrm{X})$ and oleic acid (Y) with the following rate equation:

$$
L_{\mathrm{b} k, \mathrm{X}}=L_{\mathrm{b} k, \mathrm{Y}}=k_{\mathrm{BR}, \mathrm{X}, \mathrm{Y}}[\mathrm{X}]_{\mathrm{b} k}[\mathrm{Y}]_{\mathrm{b} k}
$$

\section{Model application: oxidation of oleic acid by ozone}

To test and demonstrate the applicability of the KM-SUB model, we simulated the oxidation of oleic acid particles by ozone in comparison to experimental data from Ziemann (2005). The same data set has recently been used by Pfrang et al. (2009) for simulations with a kinetic doublelayer model (K2-SUB; Appendix C). The gas phase ozone concentration was set to $[\mathrm{X}]_{\mathrm{g}}=[\mathrm{X}]_{\mathrm{gs}}=7.0 \times 10^{13} \mathrm{~cm}^{-3}$ (corresponding to $2.8 \mathrm{ppm}$ at $1013 \mathrm{hPa}$ and $298 \mathrm{~K}$ ). The initial surface and bulk concentrations of ozone $(\mathrm{X})$ were set to 
Table 1. Kinetic parameters for the interaction of ozone $(\mathrm{X})$ and oleic acid (Y) in different model scenarios (base cases 1-3).

\begin{tabular}{|c|c|c|c|}
\hline Parameter & Base case 1 & Base case 2 & Base case 3 \\
\hline$\alpha_{\mathrm{s}, 0, \mathrm{X}}$ & $4.2 \times 10^{-4}$ & $8.5 \times 10^{-4}$ & $4.2 \times 10^{-4}$ \\
\hline$\tau_{\mathrm{d}, \mathrm{X}}(\mathrm{s})$ & 0.01 & 0.001 & 0.01 \\
\hline$D_{\mathrm{b}, \mathrm{X}}\left(\mathrm{cm}^{2} \mathrm{~s}^{-1}\right)$ & $10^{-5}$ & $10^{-5}$ & $10^{-10}$ \\
\hline$D_{\mathrm{b}, \mathrm{Y}}\left(\mathrm{cm}^{2} \mathrm{~s}^{-1}\right)$ & $10^{-10}$ & $10^{-10}$ & $10^{-15}$ \\
\hline$k_{\mathrm{SLR}, \mathrm{X}, \mathrm{Y}}\left(\mathrm{cm}^{2} \mathrm{~s}^{-1}\right)$ & $6.0 \times 10^{-12}$ & $6.0 \times 10^{-12}$ & $6.0 \times 10^{-12}$ \\
\hline$k_{\mathrm{BR}, \mathrm{X}, \mathrm{Y}}\left(\mathrm{cm}^{3} \mathrm{~s}^{-1}\right)$ & $1.7 \times 10^{-15}$ & $5.0 \times 10^{-17}$ & $1.7 \times 10^{-15}$ \\
\hline
\end{tabular}

$[\mathrm{X}]_{\mathrm{s}, 0}=[\mathrm{X}]_{\mathrm{b} k, 0}=0$, and the initial surface and bulk concentrations of oleic acid $(\mathrm{Y})$ were set to $[\mathrm{Y}]_{\mathrm{ss}, 0}=9.7 \times 10^{13} \mathrm{~cm}^{-2}$ and $[\mathrm{Y}]_{\mathrm{ss}, 0}=1.2 \times 10^{21} \mathrm{~cm}^{-3}$, respectively. Accordingly, the initial value of the total number of oleic acid molecules in particles with a radius of $0.2 \mu \mathrm{m}$ was $N_{\mathrm{Y}, 0}=4.1 \times 10^{7}$.

We modeled the temporal evolution of the particle surface and bulk composition and of the ozone uptake coefficient by numerically solving the differential equations of mass balance for each model compartment with Matlab software (ode23tb solver with 999 time steps). The rate equations describing the ozone - oleic acid reaction system are listed in Appendix D. The kinetic parameters required for the model simulations are summarized in Table 1: the surface accommodation coefficient of ozone $\left(\alpha_{\mathrm{s}, 0, \mathrm{X}}\right)$, the desorption lifetime of ozone $\left(\tau_{\mathrm{d}, \mathrm{X}}\right)$, the bulk diffusion coefficients of ozone and oleic acid $\left(D_{\mathrm{b}, \mathrm{X}}, D_{\mathrm{b}, \mathrm{Y}}\right)$, the secondorder surface layer reaction rate coefficient $\left(k_{\mathrm{SLR}, X, Y}\right)$, and the second-order bulk reaction rate coefficient $\left(k_{\mathrm{BR}, \mathrm{X}, \mathrm{Y}}\right)$. Additional input parameters were the mean thermal velocity of ozone $\left(\omega_{\mathrm{X}}=3.6 \times 10^{4} \mathrm{~cm} \mathrm{~s}^{-1}\right)$, the Henry's law coefficient $\left(K_{\mathrm{sol}, \mathrm{cc}, \mathrm{X}}=4.8 \times 10^{-4} \mathrm{~mol} \mathrm{~cm}^{-3} \mathrm{~atm}^{-1}\right)$, and the molecular diameters of oleic acid $\left(\delta_{\mathrm{Y}}=0.8 \mathrm{~nm}\right)$ and ozone $\left(\delta_{\mathrm{X}}=0.4 \mathrm{~nm}\right)$ (Pfrang et al., 2009). The model simulations were performed with $n=100$ layers corresponding to a layer thickness of $\delta=1.99 \mathrm{~nm}$ for $r_{\mathrm{p}}=0.2 \mu \mathrm{m}$, unless mentioned otherwise. For simplicity the physico-chemical parameters were assumed to be constant throughout each model run.

The first-generation products of oleic acid oxidation by ozone are mainly 1-nonanal, 9-oxononanoic acid, nonanoic acid, and azelaic acid (Moise and Rudich, 2002; Katrib et al., 2004; Thornberry and Abbatt, 2004; Vesna et al., 2009). 1-Nonanal is highly volatile and likely to evaporate from the particle (Sage et al., 2009). The other products, however, have higher molecular masses and are more polar, less volatile and likely to remain in the condensed phase (Jimenez et al., 2009). Moreover, they may undergo recombination reactions forming second-generation products of higher molecular mass such as dimers or oligomers in the bulk (Rudich et al., 2007, and references therein). These effects go beyond the scope of the present study, but the gas-particle partitioning of (semi-)volatile species and the effects of chem- ical transformation on particle size and properties shall be incorporated in follow-up studies.

Here we focus on three model scenarios (base cases) characterizing the influence of different parameters and conditions on the uptake of ozone and the decay of oleic acid. The derivation and choice of kinetic parameters were discussed in detail by Pfrang et al. (2009). In view of the uncertainties and limited availability of experimental data we compare three cases covering a range of plausible parameter variations.

In base case 1 (BC1, kinetic limitation by interfacial transport) we assumed fast bulk reaction with a literature-derived rate coefficient of $k_{\mathrm{BR}, \mathrm{X}, \mathrm{Y}}=1.7 \times 10^{-15} \mathrm{~cm}^{3} \mathrm{~s}^{-1}$ (equivalent to $10^{6} \mathrm{~L} \mathrm{~mol}^{-1} \mathrm{~s}^{-1}$ ) (Titov et al., 2005). The surface reaction rate coefficient $k_{\mathrm{SLR}, \mathrm{X}, \mathrm{Y}}=6 \times 10^{-12} \mathrm{~cm}^{2} \mathrm{~s}^{-1}$ was adopted from Pfrang et al. (2009). Note that this value is an order of magnitude lower than reported value by other studies (Gonzalez-Labrada et al., 2007; King et al., 2009). Bulk diffusion coefficients were adopted from earlier studies $\left(D_{\mathrm{b}, \mathrm{X}}=10^{-5} \mathrm{~cm}^{2} \mathrm{~s}^{-1}, D_{\mathrm{b}, \mathrm{Y}}=10^{-10} \mathrm{~cm}^{2} \mathrm{~s}^{-1}\right)$ (Smith et al., 2002, 2003), and the parameters of reversible adsorption were adjusted to match the experimental data of oleic acid decay $\left(\alpha_{\mathrm{s}, 0, \mathrm{X}}=4.2 \times 10^{-4}\right.$ and $\left.\tau_{\mathrm{d}, \mathrm{X}}=0.01 \mathrm{~s}\right)$.

In base case 2 (BC2, kinetic limitation by bulk reaction) we assumed slow bulk reaction with a rate coefficient $\sim 30$ times lower than in $\mathrm{BC} 1\left(k_{\mathrm{BR}, \mathrm{X}, \mathrm{Y}}=5 \times 10^{-17} \mathrm{~cm}^{3} \mathrm{~s}^{-1}\right)$. The adsorption parameters were re-adjusted to match the experimental data $\left(\alpha_{\mathrm{s}, 0, \mathrm{X}}=8.5 \times 10^{-4}, \tau_{\mathrm{d}, \mathrm{X}}=0.001 \mathrm{~s}\right)$, and all other parameters were kept equal to $\mathrm{BC} 1$. Note that in $\mathrm{BC} 1$ and $\mathrm{BC} 2$ the results can be reproduced with different combinations of $\alpha_{\mathrm{s}, 0, \mathrm{X}}$ and $\tau_{\mathrm{d}, \mathrm{X}}$, that are closer to prediction of molecular dynamic simulations (e.g., $\alpha_{\mathrm{s}, 0, \mathrm{X}} \approx 10^{-2}$ and $\tau_{\mathrm{d}, \mathrm{X}} \approx 10^{-9}$ s) (Vieceli et al., 2005; Shiraiwa et al., 2009). These aspects will be further investigated in follow-up studies.

In base case 3 (BC3, kinetic limitation by bulk diffusion) we assumed slow mass transport in the bulk with diffusion coefficients that are characteristic for amorphous (semi-)solid matrices (Bird et al., 2007; Swallen et al., 2007; Mikhailov et al., 2009) and five orders of magnitude lower than in $\mathrm{BC} 1$ and BC2 $\left(D_{\mathrm{b}, \mathrm{X}}=10^{-10} \mathrm{~cm}^{2} \mathrm{~s}^{-1}\right.$ and $D_{\mathrm{b}, \mathrm{Y}}=$ $\left.10^{-15} \mathrm{~cm}^{2} \mathrm{~s}^{-1}\right)$.

\subsection{Base case 1: kinetic limitation by interfacial transport}

Figure 2 illustrates the model results of KM-SUB in base case 1 with the kinetic parameters specified in Table 1. As shown in Fig. 2a, the simulated decay of oleic acid is in very good agreement with the experimentally observed decay. Throughout the experimental time scale of 1-15 s, the simulated ozone uptake coefficient is nearly constant and identical to the surface and bulk accommodation coefficients $\left(\gamma_{\mathrm{X}} \approx \alpha_{\mathrm{b}, \mathrm{X}} \approx \alpha_{\mathrm{s}, \mathrm{X}} \approx \alpha_{\mathrm{s}, 0, \mathrm{X}} \approx 4 \times 10^{-4}\right)$, indicating that the gas uptake is limited by interfacial mass transport, i.e., by the process of bulk accommodation which is in turn 
limited by the process of surface accommodation. After $\sim 30$ s the ozone uptake coefficient rapidly drops off when reaction partner oleic acid is used up by the rapid bulk reaction $\left(\gamma_{\mathrm{X}} / \gamma_{\mathrm{X}, 0} \approx N_{\mathrm{Y}} / N_{\mathrm{Y}, 0}<1 \%\right.$ after $\left.\sim 37 \mathrm{~s}\right)$.

As shown in Fig. 2b, the surface concentration of oleic acid also decreases gradually over the first $\sim 30 \mathrm{~s}$ and drops off rapidly afterwards. In contrast, the surface concentration of ozone exhibits a rapid initial increase from zero to a plateau level of $[\mathrm{X}]_{\mathrm{s}} \approx 10^{11} \mathrm{~cm}^{-2}$, which is reached within less than a second $(\sim 20 \mathrm{~ms})$ and determined by the combination of reversible adsorption, surface reaction, and surfaceto-bulk transport driven by the chemical reaction in the bulk. Over the first $30 \mathrm{~s},[\mathrm{X}]_{\mathrm{s}}$ gradually increases with the decay of oleic acid and the related decrease of chemical loss. As the chemical loss by reaction with oleic acid rapidly drops off after $\sim 30 \mathrm{~s},[\mathrm{X}]_{\mathrm{s}}$ swiftly increases by an order of magnitude to a steady-state level of $\sim 10^{12} \mathrm{~cm}^{-2}$, which is governed by reversible adsorption.

To test how the number of model layers in the particle bulk affects the simulation results, we have run the model with $n=1,5$ and 100 layers corresponding to layer thicknesses of $\delta=199.2,39.8$ and $1.99 \mathrm{~nm}$, respectively. The results obtained with $n=100$ and 5 were practically identical, demonstrating the robustness of the multi-layer model approach with transport rate coefficients (velocities) scaled by the layer thickness (Eqs. 28-31). As shown in Fig. 2, the deviations obtained with $n=1$ were relatively minor, but they indicate that the particle bulk cannot be regarded as well mixed under the conditions of base case 1 . Similar deviations were obtained with the kinetic double-layer model K2-SUB, in which the bulk processes are not explicitly resolved but represented by a reacto-diffusive flux (Appendix C, Pfrang et al., 2009).

The KM-SUB model results for the bulk concentration profiles of ozone and oleic acid were also essentially the same with $n=100$ and 5. For high resolution and to avoid congestion of the plot, however, only the profiles obtained 100 layers are shown in Fig. 3. The y-axis indicates the radial distance from the particle center $(r)$ normalized by the particle radius $\left(r_{\mathrm{p}}\right)$, ranging from the particle core $\left(\delta / r_{\mathrm{p}} \approx 0\right)$ to the near-surface bulk $\left(\left(r_{\mathrm{p}}-\delta\right) / r_{\mathrm{p}} \approx 1\right)$.

As shown in Fig. 3a, ozone rapidly diffuses into the particle bulk. A gradient between the near-surface bulk and the core is established within less than a second $(\sim 20 \mathrm{~ms})$, and the concentration profile is determined by the interplay of interfacial mass transport (surface and bulk accommodation) with bulk diffusion and chemical reaction. During the first few seconds, the ozone concentration in the particle core is about a factor of $\sim 50$ lower than in the near surface bulk. Up to $\sim 30 \mathrm{~s}$, the ozone concentration gradient decreases gradually with the decay of oleic acid and the related decrease of chemical loss. As the chemical loss by reaction with oleic acid rapidly drops off after $\sim 30 \mathrm{~s}$, the ozone concentration gradient swiftly relaxes, and after $\sim 37 \mathrm{~s}$ ozone is well mixed throughout the particle bulk at the concentration level of sol-
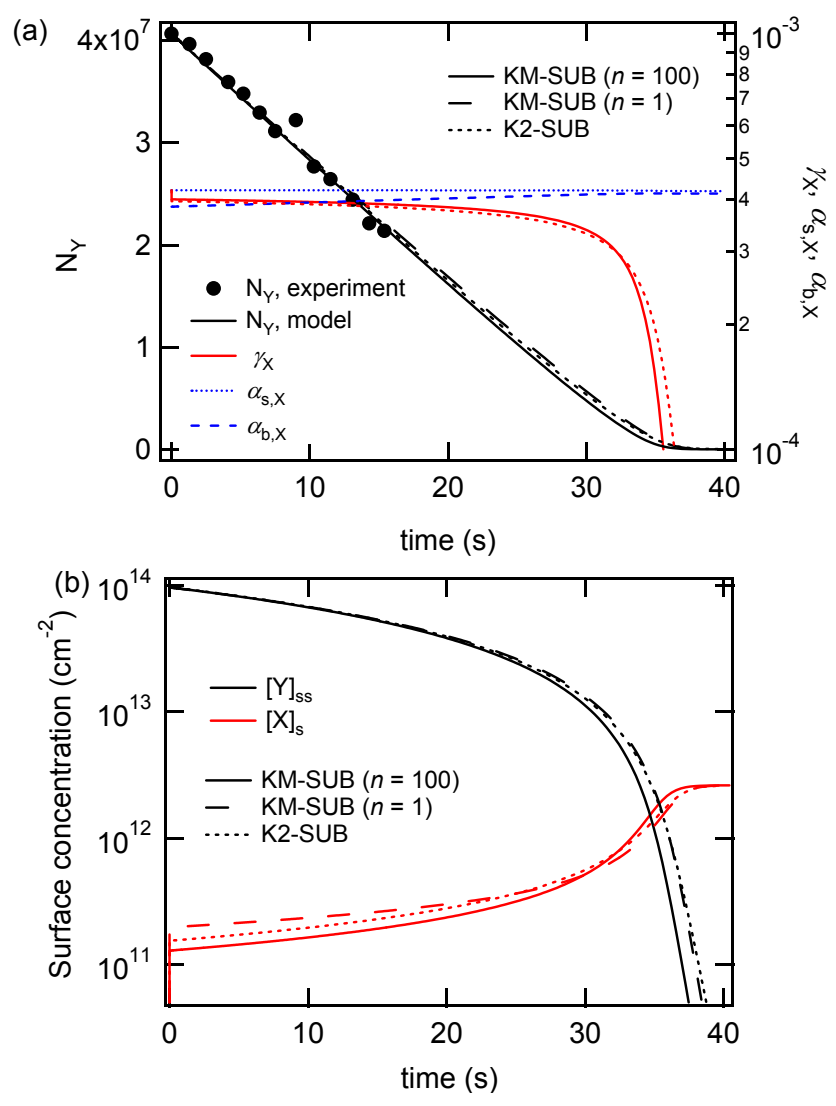

Fig. 2. Temporal evolution of model base case 1 in KM-SUB with $n=1$ (dashed lines) and $n=100$ (solid lines) and in K2-SUB (dotted lines). (a) Experimental data (black symbols; Ziemann, 2005) and model results for the total number of oleic acid molecules $\left(N_{\mathrm{Y}}\right.$, black line) and for the uptake coefficient of ozone $\left(\gamma_{X_{i}}\right.$, red line), surface accommodation coefficient $\left(\alpha_{\mathrm{S}, \mathrm{X}}\right.$, blue dotted line), and bulk accommodation coefficient ( $\alpha_{\mathrm{b}, \mathrm{X}}$, blue dashed line). (b) Surface concentrations of oleic acid (black line) and ozone (red line).

ubility saturation $\left([\mathrm{X}]_{\mathrm{b}, \mathrm{sat}}=8 \times 10^{14} \mathrm{~cm}^{-3}=K_{\mathrm{sol}, \mathrm{CC}, \mathrm{X}}[\mathrm{X}]_{\mathrm{gs}}\right.$ with $K_{\mathrm{sol}, \mathrm{CC}, \mathrm{X}}=4.8 \times 10^{-4} \mathrm{~mol} \mathrm{~cm}^{-3} \mathrm{~atm}^{-1}$ ).

As shown in Fig. 3b, the ozone gradient and the ozonolysis of oleic acid cause a reverse gradient in the bulk concentration of oleic acid. Because the concentration of oleic acid is several orders of magnitude larger than that of ozone, however, the strong gradient of ozone induces only a small gradient in oleic acid. During the first few seconds, the oleic acid concentration in the near-surface bulk is $\sim 5 \%$ lower than in the particle core. As the ozone gradient relaxes after $\sim 30 \mathrm{~s}$, the small oleic acid gradient also disappears. Thus, oleic acid can effectively be regarded as well-mixed.

Figure 4a shows the loss rate of oleic acid and ozone by chemical reaction in the particle bulk $\left(L_{\mathrm{b}}\right)$ as calculated with KM-SUB for different model layers and with KM-SUB and K2-SUB effectively averaged over the whole bulk volume. The averaged values of $L_{\mathrm{b}}$ calculated by K2-SUB and KM-SUB are almost identical, demonstrating consistency 

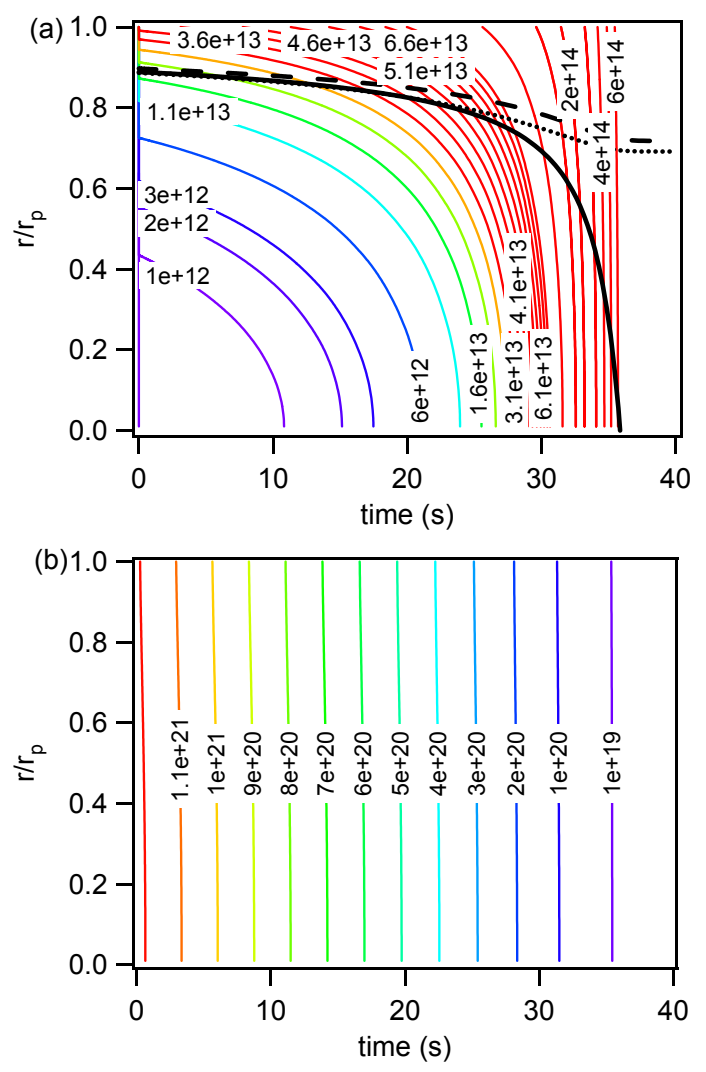

Fig. 3. Temporal evolution of bulk concentration profiles for model base case 1 for (a) ozone and (b) oleic acid (KM-SUB with $n=$ 100). The $y$-axis indicates the radial distance from the particle center $(r)$ normalized by the particle radius, ranging from the particle core $\left(r / r_{\mathrm{p}}=\delta / r_{\mathrm{p}} \approx 0\right)$ to the near-surface bulk $\left(r / r_{\mathrm{p}}=1\right)$. The colored lines are isopleths of bulk concentration with labeled in units of $\mathrm{cm}^{-3}$ (blue=low, red=high). The black solid line represents the reacto-diffusive length for ozone normalized by the particle radius $\left(1-l_{\mathrm{rd}, \mathrm{X}} / r_{\mathrm{p}}\right)$. The black dotted line represents the $50 \%$ isoline for the concentration difference between the particle core and the nearsurface bulk, and the black dashed line shows $63 \%$ isoline of $L_{\mathrm{b}}^{*}$.

of KM-SUB with K2-SUB and with the underlying resistor model formulation of the reacto-diffusive flux $J_{\mathrm{b}, \mathrm{rd}}$. Due to the overall kinetic limitation by interfacial transport, the volume-average loss rate $L_{\mathrm{b}}$ remains near-constant up to $\sim 30$ s. During the first few seconds, the loss rate in the nearsurface bulk $\left(L_{\mathrm{b} 1}, r / r_{\mathrm{p}} \approx 1\right)$ is more than a factor of 2 higher than the volume-average loss rate, while the loss rates in layers around the particle core $\left(L_{\mathrm{b} 40}\right.$ to $\left.L_{\mathrm{b} 100}, r / r_{\mathrm{p}}<0.6\right)$ are more than a factor of 2 lower. $L_{\mathrm{b} 1}$ continually decreases due to progressing consumption of oleic acid, whereas $L_{\mathrm{b} 40}$ to $L_{\mathrm{b} 100}$ exhibit a pronounced increase up to $\sim 35 \mathrm{~s}$ due to the penetration of ozone to the particle core (see also Fig. 3a). After $\sim 35 \mathrm{~s}$ all loss rates drop off rapidly and approach zero after $\sim 37 \mathrm{~s}$ as oleic acid is essentially used up.

Up to $\sim 30 \mathrm{~s}$, the strong radial gradient of loss rates $L_{\mathrm{b}}$ and the approximate coincidence of $L_{\mathrm{b} 20}\left(r / r_{\mathrm{p}} \approx 0.8\right)$ with $L_{\mathrm{b}}$ in-
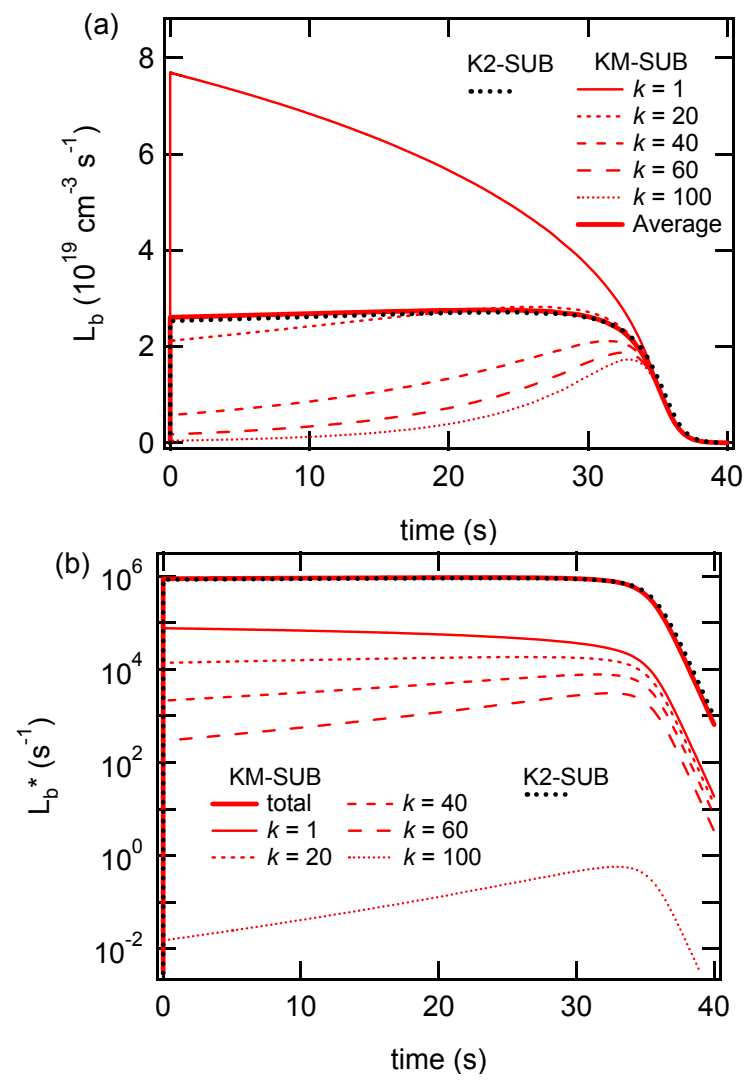

Fig. 4. (a) Loss rate $\left(L_{\mathrm{b}}\right)$ and (b) absolute loss rate $\left(L_{\mathrm{b} k}^{*}\right)$ of oleic acid in the bulk calculated by KM-SUB for bulk layers 1 (nearsurface bulk), 20, 40, 60, and 100 (core) in BC1. $L_{\mathrm{b}}$ calculated by K2-SUB and volume average $L_{\mathrm{b}}\left(=L_{\mathrm{b}}^{*} / V_{\mathrm{b}}\right)$ calculated by KMSUB are shown in panel (a). Total absolute los rate $\left(L_{\mathrm{b}}^{*}\right)$ calculated by KM-SUB and K2-SUB are also shown in panel (b).

dicate that the overall rate of conversion or absolute loss rate of oleic acid and ozone molecules in the particle is strongly dominated by the outer bulk layers at $r / r_{\mathrm{p}}>0.8$. Due to the spherical geometry the outer layers also have much larger volumes, which further enhances their relative importance with regard to the absolute loss rate of molecules in each layer $\left(L_{\mathrm{b} k}^{*}=L_{\mathrm{b} k} V_{\mathrm{b} k}\right)$ and in the entire particle $\left(L_{\mathrm{b}}^{*}=L_{\mathrm{b}} V_{\mathrm{b}}\right)$. Figure $4 \mathrm{~b}$ illustrates this by displaying the values of $L_{\mathrm{b} k}^{*}$ and $L_{\mathrm{b}}^{*}$ corresponding to the values of $L_{\mathrm{b} k}$ and $L_{\mathrm{b}}$ displayed in Fig. $4 \mathrm{a}$ (note the linear scaling of Fig. $4 \mathrm{a}$ and the logarithmic scaling of Fig. $4 \mathrm{~b}$ ). $L_{\mathrm{b}}^{*}$ calculated by KM-SUB and K2-SUB are almost identical.

The black solid line in Fig. 3a represents the reactodiffusive length for ozone normalized by the particle radius $\left(1-l_{\mathrm{rd}, \mathrm{X}} / r_{\mathrm{p}}\right)$, which can be regarded as the distance from the surface up to which the chemical reaction proceeds effectively (Finlayson-Pitts and Pitts, 2000; Pöschl et al., 2007). The initial value of $l_{\mathrm{rd}, \mathrm{X}} \approx 20 \mathrm{~nm}$ is consistent with the values reported by Smith et al. (2003) and Katrib et al. (2004). Over the first $\sim 30 \mathrm{~s}$ of the model run $l_{\mathrm{rd}, \mathrm{X}}$ remains fairly constant, 
and the reacto-diffusive line (black solid) coincides with the $50 \%$ isoline for the concentration difference between the particle core and the near-surface bulk (black dotted), and with the $63 \%(=1-1 / \mathrm{e})$ isoline of $L_{\mathrm{b}}^{*}$ (black dashed). During this time $63 \%$ of $L_{\mathrm{b}}^{*}$, i.e., $63 \%$ of the overall rate of conversion of oleic acid ozonolysis, occur in the outermost 10 bulk layers, i.e. at $r / r_{\mathrm{p}}>0.9$ (corresponding to $\sim 30 \%$ of the particle bulk volume). After $\sim 30 \mathrm{~s}, l_{\mathrm{rd}, \mathrm{X}}$ increases steeply as oleic acid is depleted and ozone can freely penetrate throughout the bulk of the particle.

\subsection{Base case 2: kinetic limitation by bulk reaction}

In base case 2 the second-order bulk reaction rate coefficient was by a factor of $\sim 30$ smaller than in $\mathrm{BC} 1$, while the surface accommodation coefficient was by a factor of $\sim 2$ higher (Table 1). As shown in Fig. 5a, the simulation results of $\mathrm{BC} 2$ are also in very good agreement with the observed decay of oleic acid. The calculated ozone uptake coefficient behaves very differently than in $\mathrm{BC} 1$. The initial value of $\gamma_{\mathrm{X}}$ in $\mathrm{BC} 2$ is by a factor of $\sim 2$ higher than in $\mathrm{BC} 1$. It reflects rapid uptake into the initially ozone-free particle bulk, which is limited by the kinetics of interfacial transport, i.e., bulk accommodation and surface accommodation, respectively. After less than one second $(\sim 20 \mathrm{~ms})$, however, $\gamma_{X}$ steeply drops off to a level that is reaction-limited $\left(\gamma_{\mathrm{X}} \approx 10^{-4}<\alpha_{\mathrm{b}, \mathrm{X}} \approx 8 \times 10^{-4}\right)$ and continues to decrease gradually with decreasing abundance of the reaction partner oleic acid.

After a rapid initial increase $(\sim 20 \mathrm{~ms})$, the ozone surface concentration reaches a plateau level which increases only slightly until the end of the simulation, while the oleic acid surface concentration decreases gradually. In contrast to $\mathrm{BC} 1$, none of the compositional and kinetic parameters exhibit abrupt changes after $\sim 30 \mathrm{~s}$. Instead, they all undergo a gradual evolution reflecting the kinetics of the rate-limiting bulk reaction.

The results of multi-layer model KM-SUB with both $n=$ 100 and 1 were practically identical to the results of the double-layer model K2-SUB, indicating that the particle bulk can be regarded as well mixed under the conditions of $\mathrm{BC} 2$.

Due to faster interfacial transport and slower chemical reaction, the ozone concentration in the bulk increases much faster than in BC1 (Fig. 6a vs. Fig. 3a). After less than one second $(\sim 20 \mathrm{~ms})$, the ozone concentration in the core of the particle is only $\sim 30 \%$ lower than in the near-surface bulk, and the gradient continues to decrease with decreasing abundance of oleic acid. Due to the slow decay of oleic acid, however, a small ozone gradient persists until the end of the simulation (Fig. 6a) and thus longer than in BC1, where the initially very strong gradient essentially disappears after $\sim 37 \mathrm{~s}$ when practically all oleic acid $(>99 \%)$ has been consumed by the rapid bulk reaction (Fig. 3a). As illustrated in Fig. 6b, oleic acid can be regarded as well-mixed (concentration differences $<1 \%$ ).
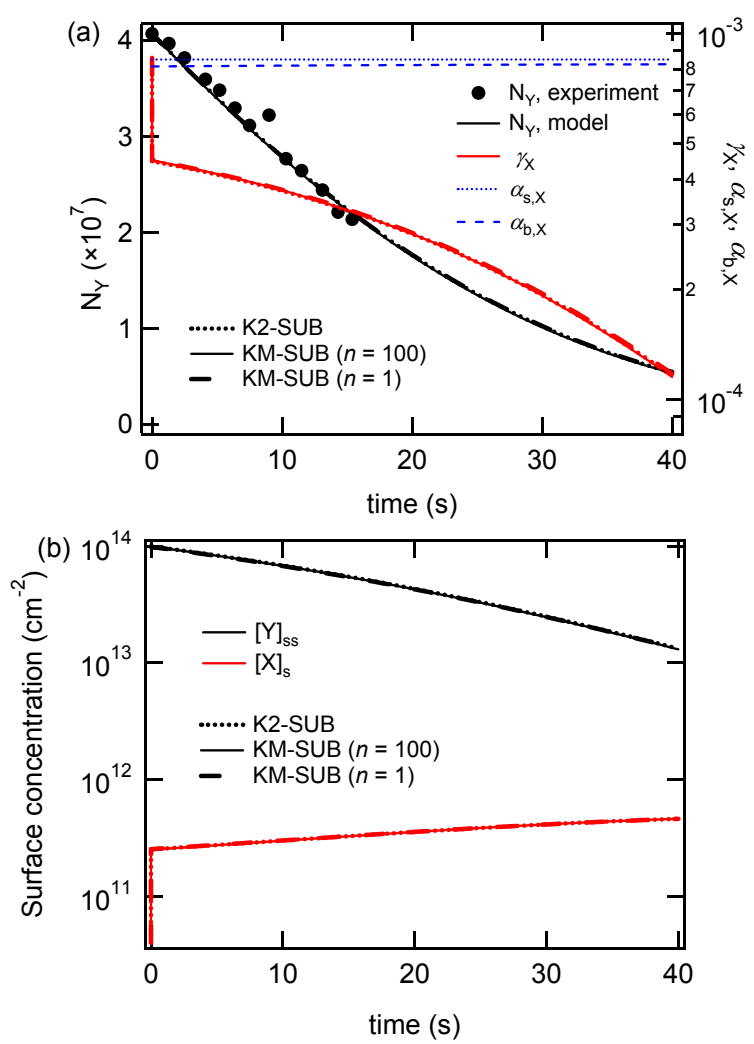

Fig. 5. Temporal evolution of model base case 2 in KM-SUB with $n=1$ (dashed lines) and $n=100$ (solid lines) and in K2-SUB (dotted lines). (a) Experimental data (black symbols; Ziemann, 2005) and model results for the total number of oleic acid molecules $\left(N_{\mathrm{Y}}\right.$, black line) and for the uptake coefficient of ozone ( $\gamma_{\mathrm{X}}$, red line $)$, surface accommodation coefficient $\left(\alpha_{\mathrm{S}, \mathrm{X}}\right.$, blue dotted line), and bulk accommodation coefficient ( $\alpha_{\mathrm{b}, \mathrm{X}}$, blue dashed line). (b) Surface concentrations of oleic acid (black line) and ozone (red line).

Figure 7a shows the loss rate of oleic acid and ozone by chemical reaction in the particle bulk $\left(L_{\mathrm{b}}\right)$ as calculated with KM-SUB for different model layers and with KM-SUB and K2-SUB effectively averaged over the whole bulk volume. The average values of $L_{\mathrm{b}}$ calculated by K2-SUB and KMSUB are almost identical. Due to the kinetic limitation by bulk reaction, the volume-average loss rate $L_{\mathrm{b}}$ decreases continuously due to consumption of oleic acid. Initially, $L_{\mathrm{b}}$ in the near-surface bulk $\left(L_{\mathrm{b} 1}, r / r_{\mathrm{p}} \approx 1\right)$ is $\sim 40 \%$ higher than that in the core $\left(L_{\mathrm{b} 100}\right)$ corresponding to the concentration gradient of $\mathrm{O}_{3}$ in the bulk. They become almost same in 20 $\mathrm{s}$ as concentration gradient becomes smaller. Figure $7 \mathrm{~b}$ illustrates $L_{\mathrm{b} k}^{*}\left(=L_{\mathrm{b} k} V_{\mathrm{b} k}\right)$ and $L_{\mathrm{b}}^{*}\left(=L_{\mathrm{b}} V_{\mathrm{b}}\right)$ corresponding to the values of $L_{\mathrm{b} k}$ and $L_{\mathrm{b}}$ displayed in Fig. 7a (note the linear scaling of Fig. $7 \mathrm{a}$ and the logarithmic scaling of Fig. $7 \mathrm{~b}$ ). $L_{\mathrm{b}}^{*}$ calculated by KM-SUB and K2-SUB are almost identical.

The black solid line in Fig. 6a represents again the reactodiffusive length for ozone normalized by the particle radius $\left(1-l_{\mathrm{rd}, \mathrm{X}} / r_{\mathrm{p}}\right)$. Due to the lower reaction rate coefficient, the initial value of $l_{\mathrm{rd}, \mathrm{X}} \approx 120 \mathrm{~nm}$ is by a factor of $\sim 6$ larger 

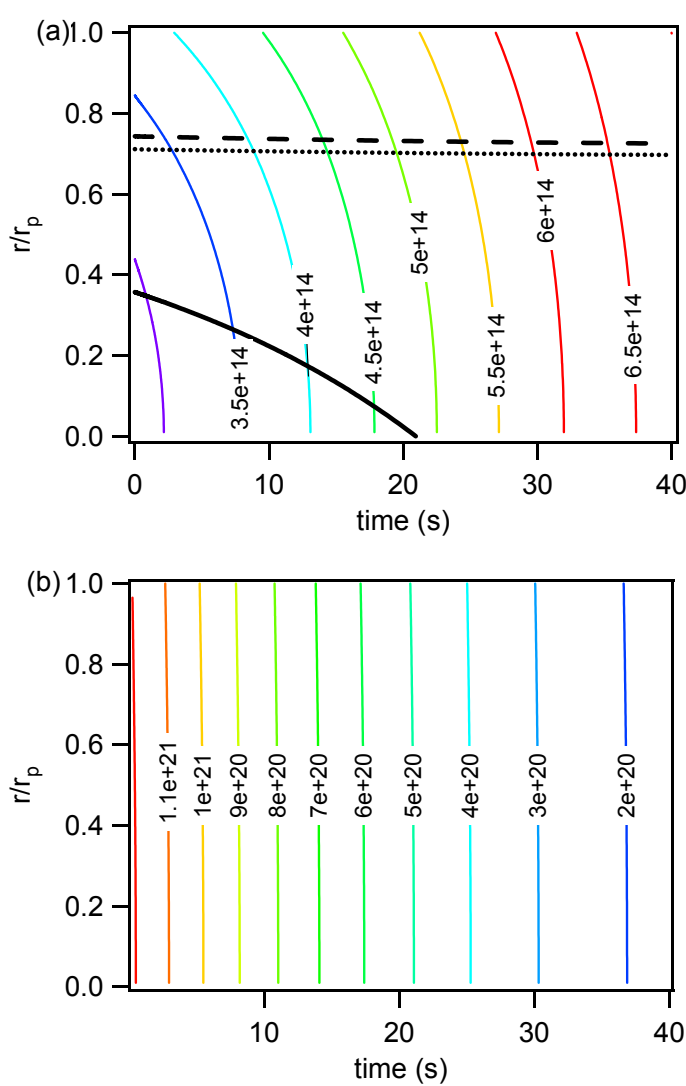

Fig. 6. Temporal evolution of bulk concentration profiles for model base case 1 for (a) ozone and (b) oleic acid (KM-SUB with $n=$ 100). The y-axis indicates the radial distance from the particle center $(r)$ normalized by the particle radius, ranging from the particle core $\left(r / r_{\mathrm{p}}=\delta / r_{\mathrm{p}} \approx 0\right)$ to the near-surface bulk $\left(r / r_{\mathrm{p}}=1\right)$. The colored lines are isopleths of bulk concentration with labeled in units of $\mathrm{cm}^{-3}$ (blue=low, red=high). The black solid line represents the reacto-diffusive length for ozone normalized by the particle radius $\left(1-l_{\mathrm{rd}, \mathrm{X}} / r_{\mathrm{p}}\right)$. The black dotted line represents the $50 \%$ isoline for the concentration difference between the particle core and the nearsurface bulk, and the black dashed line shows $63 \%$ isoline of $L_{\mathrm{b}}^{*}$.

than in $\mathrm{BC} 1$, and after $\sim 20 \mathrm{~s}$ it is already larger than the particle radius $(200 \mathrm{~nm})$, indicating that the reaction effectively proceeds throughout the whole bulk. The $50 \%$ isoline (black dotted) for the ozone concentration difference between the particle core and the near-surface bulk and the 63\% $(=1-1 / \mathrm{e})$ isoline of $L_{\mathrm{b}}^{*}$ (black dashed) remain near-constant throughout the simulation. They are from the beginning at the same level reached at the end of $\mathrm{BC} 1$, which reflects that both ozone and oleic can be regarded as well mixed in $\mathrm{BC} 2$ due to slow reaction and rapid diffusion.

$\mathrm{BC} 1$ may be regarded as more realistic, because it uses the only reported value of the bulk reaction rate coefficient of ozone with oleic acid, whereas $\mathrm{BC} 2$ assumes a $\sim 30$ times lower value. Nevertheless, both model cases are in good agreement with the available experimental data. Thus, fur-
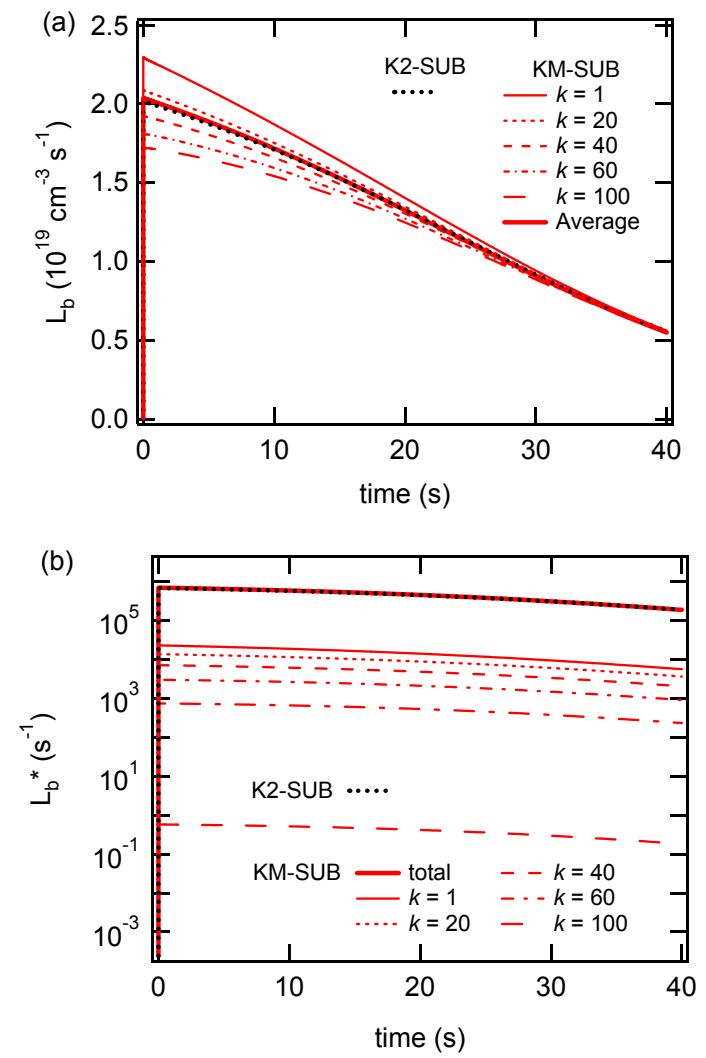

Fig. 7. (a) Loss rate $\left(L_{\mathrm{b}}\right)$ and (b) absolute loss rate $\left(L_{\mathrm{b} k}^{*}\right)$ of oleic acid in the bulk calculated by KM-SUB for bulk layers 1 (nearsurface bulk), 20, 40, 60, and 100 (core) in BC2. $L_{\mathrm{b}}$ calculated by K2-SUB and volume average $L_{\mathrm{b}}\left(=L_{\mathrm{b}}^{*} / V_{\mathrm{b}}\right)$ calculated by KMSUB are shown in panel (a). Total absolute los rate $\left(L_{\mathrm{b}}^{*}\right)$ calculated by KM-SUB and K2-SUB are also shown in panel (b).

ther experiments covering a wider range of reaction times and conditions are needed to elucidate the actual reaction mechanism (see Pfrang et al., 2009).

\subsection{Base case 3: kinetic limitation by bulk diffusion}

Base case 3 is based on base case 1 but the bulk diffusion coefficients are lower by five orders of magnitude $\left(D_{\mathrm{b}, \mathrm{X}}=\right.$ $10^{-10} \mathrm{~cm}^{2} \mathrm{~s}^{-1}, D_{\mathrm{b}, \mathrm{Y}}=10^{-15} \mathrm{~cm}^{2} \mathrm{~s}^{-1}$, Table 1), corresponding to characteristic diffusivities of amorphous (semi-)solid matrices (Bird et al., 2007; Swallen et al., 2007; Mikhailov et al., 2009).

As illustrated in Fig. 8a, the decay of oleic acid is very slow in $\mathrm{BC} 3$ because the low diffusivity effectively protects oleic acid in the particle bulk from oxidation. Within $\sim 1 \mathrm{~s}$ the calculated ozone uptake coefficient drops from the initial value of $\sim 4 \times 10^{-3}$ to $\sim 2 \times 10^{-5}$, which is due to a rapid decrease of the oleic acid surface concentration from $\sim 10^{14} \mathrm{~cm}^{-2}$ to $\sim 10^{12} \mathrm{~cm}^{-2}$. After $\sim 1 \mathrm{~s}$ the ozone surface concentration remains practically constant at $\sim 10^{12} \mathrm{~cm}^{-2}$ (adsorption equilibrium). The low levels of ozone uptake 
(a)
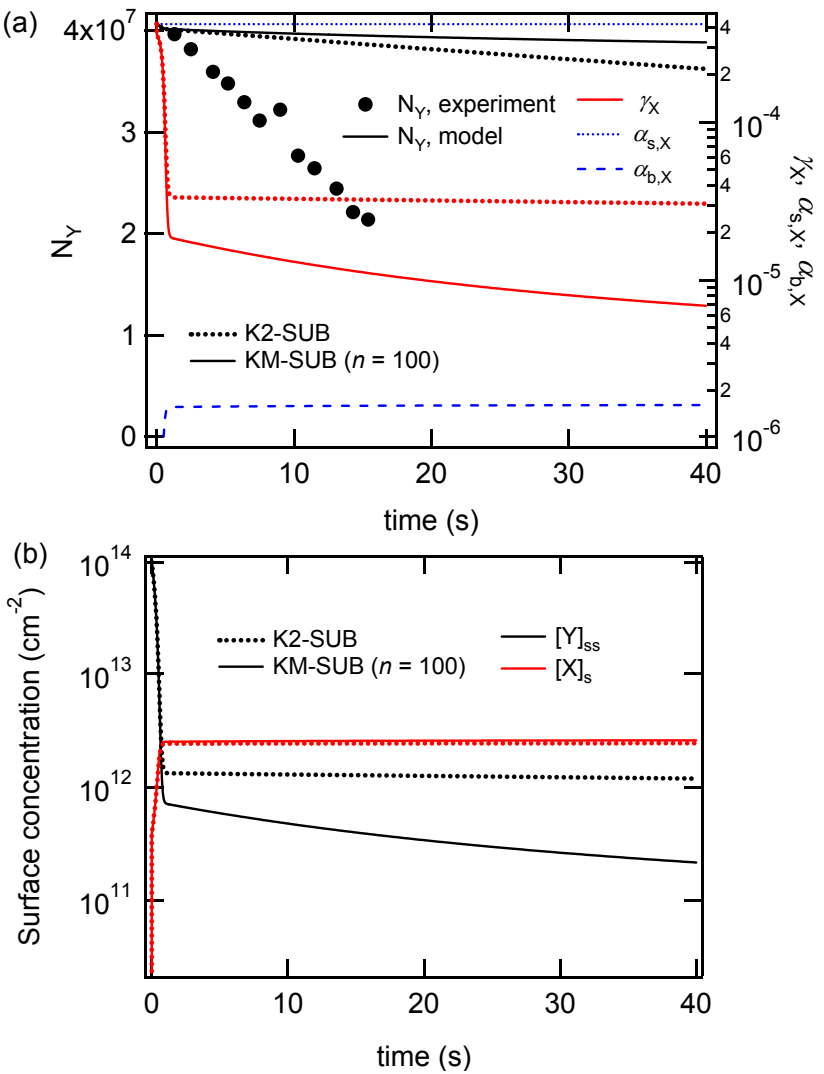

Fig. 8. Temporal evolution of model base case 3 with KM-SUB $(n=100)$. (a) Experimental data (black symbols; Ziemann, 2005) and model results for the total number of oleic acid molecules $\left(N_{\mathrm{Y}}\right.$, black line) and for the uptake coefficient of ozone $\left(\gamma_{\mathrm{X}}\right.$, red line), surface accommodation coefficient $\left(\alpha_{\mathrm{s}, \mathrm{X}}\right.$, blue dotted line), and bulk accommodation coefficient $\left(\alpha_{\mathrm{b}, \mathrm{X}}\right.$, blue dashed line). (b) Surface concentrations of oleic acid (black line) and ozone (red line).

coefficient and oleic acid surface concentration are maintained by surface bulk exchange and decrease slowly as ozone increases and oleic acid decreases also in the nearsurface bulk. In contrast to $\mathrm{BC} 1$, the bulk accommodation coefficient $\alpha_{\mathrm{b}}, \mathrm{X}\left(\approx 2 \times 10^{-6}\right)$ is much smaller than $\alpha_{\mathrm{s}, \mathrm{X}}$ and $\gamma_{\mathrm{X}}$, reflecting the slow uptake of ozone into the particle bulk, which is limited by the kinetics of surface-bulk exchange and bulk diffusion.

Due to fast reaction and slow diffusion, both ozone and oleic acid exhibit steep concentration gradients near the surface, whereas the inner particle bulk remains nearly unchanged (Fig. 9). During the simulation period ozone penetrates only into the near-surface bulk, and thus the chemical consumption of oleic acid is also restricted to the nearsurface bulk $\left(r / r_{\mathrm{p}}>0.99\right)$. Accordingly, the reacto-diffusive length is very small $(\sim 0.1 \mathrm{~nm}$; black solid line in Fig. 9a), and the 50\% isoline (black dotted) for the ozone concentration difference between particle core and near-surface bulk as well as the $63 \%(=1-1 / \mathrm{e})$ isoline of $L_{\mathrm{b}}^{*}$ (black dashed)
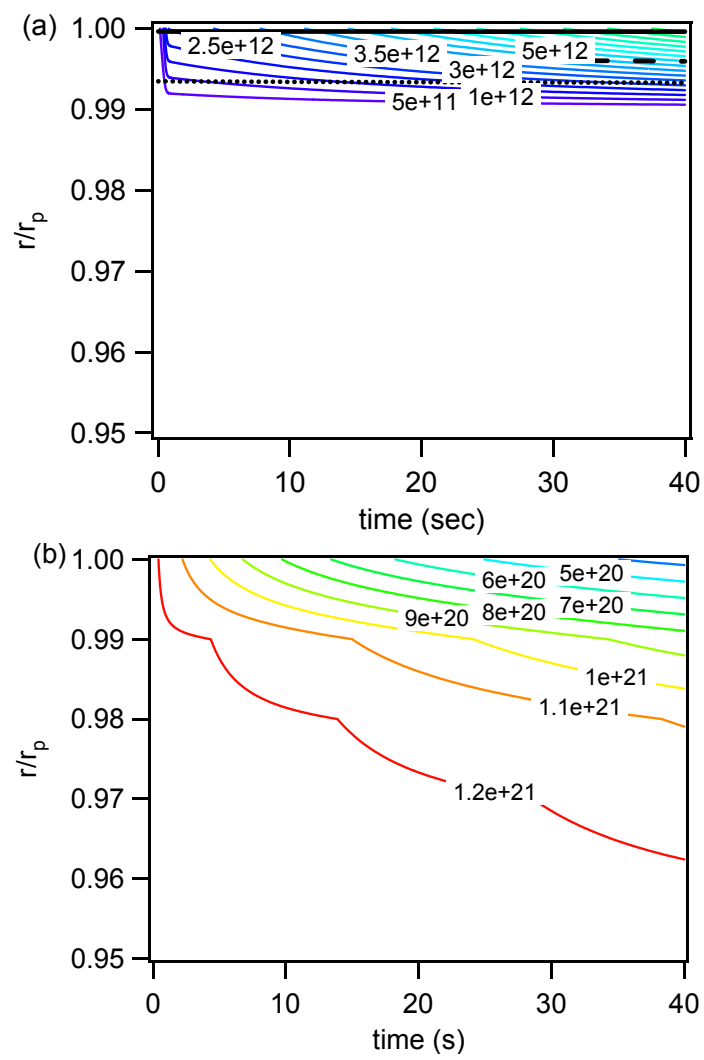

Fig. 9. Temporal evolution of bulk concentration profiles for model base case 3 for (a) ozone and (b) oleic acid (KM-SUB with $n=$ 100). The $y$-axis indicates the radial distance from the particle center $(r)$ normalized by the particle radius, ranging from $r / r_{\mathrm{p}}=0.95$ to the near-surface bulk $\left(r / r_{\mathrm{p}}=1\right)$. The colored lines are isopleths of bulk concentration with labeled in units of $\mathrm{cm}^{-3}$ (blue=low, red=high). The black solid line represents the reacto-diffusive length for ozone normalized by the particle radius $\left(1-l_{\mathrm{rd}, \mathrm{X}} / r_{\mathrm{p}}\right)$. The black dotted line represents the $50 \%$ isoline for the concentration difference between the particle core and the near-surface bulk, and the black dashed line shows $63 \%$ isoline of $L_{\mathrm{b}}^{*}$.

remain restricted to the near surface bulk $\left(r / r_{\mathrm{p}}>0.99\right)$. This is also reflected in Fig. 10, showing that the values of $L_{\mathrm{b}}$ and $L_{\mathrm{b}}^{*}$ are essentially zero except for $k=1$ (near-surface bulk layer).

Compared to KM-SUB, the simulated decay of oleic acid and ozone uptake are faster in K2-SUB. At the end of the model run $(40 \mathrm{~s})$, the total amount of oleic acid $\left(N_{\mathrm{Y}}\right)$ is lower by $\sim 10 \%$ while the surface concentration of oleic acid $\left([Y]_{\mathrm{ss}}\right)$ and the ozone uptake coefficient $\left(\gamma_{\mathrm{X}}\right)$ are higher by a factor of $\sim 5$. This is because K2-SUB assumes that oleic acid is radially well-mixed and does not resolve its concentration profile. In fact, the diffusion coefficient of oleic acid $\left(D_{\mathrm{b}, \mathrm{Y}}\right)$ does not appear in the equation for the reactodiffusive flux (Eq. C1), which represents the effects of all bulk processes in the traditional resistor model approach. In case of kinetic limitation by bulk diffusion, however, the 

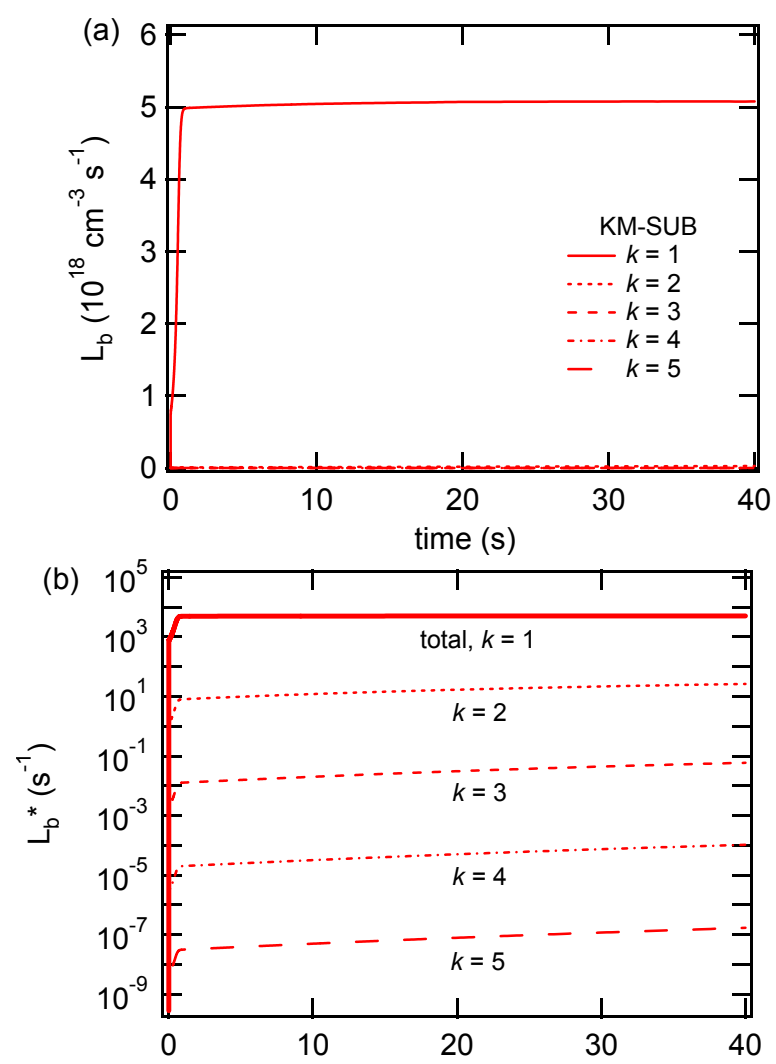

Fig. 10. (a) Loss rate $\left(L_{\mathrm{b}}\right)$ and (b) absolute loss rate $\left(L_{\mathrm{b} k}^{*}\right)$ of oleic acid in the bulk calculated by KM-SUB for bulk layers 1 (nearsurface bulk), 2, 3, 4, and 5 in BC3. Total absolute loss rate $\left(L_{\mathrm{b}}^{*}\right)$ are also shown.

reaction rates are influenced by the mass transport of both volatile and non-volatile reactants in the particle bulk.

\subsection{Chemical half-life of oleic acid and atmospheric implications}

In the preceding sections we showed how the KM-SUB model can be used to interpret and analyze experimental data from laboratory studies, which are often carried out with high $\mathrm{O}_{3}$ concentration to observe measurable effects on short experimental time scales. Here we demonstrate how the results can be extrapolated to dilute atmospheric conditions.

We estimated the chemical half-life $\left(t_{1 / 2}\right)$ of pure oleic acid particles, when exposed to ozone at average ambient mixing ratios $(<150 \mathrm{ppb})$. The radii of oleic acid particles $\left(r_{\mathrm{p}}\right)$ were set to be 0.2 and $1.0 \mu \mathrm{m}$. The chemical half-life was defined as the time when number of oleic acid molecules was degraded to half of its initial value. The solid lines of Fig. 11 show the results of such calculations with $\mathrm{BC} 1$. At typical atmospheric $\mathrm{O}_{3}$ mixing ratios of $30 \mathrm{ppb}, t_{1 / 2}$ was $\sim 25 \mathrm{~min}$ for $r_{\mathrm{p}}=0.2 \mu \mathrm{m}$ and $\sim 130 \mathrm{~min}$ for $r_{\mathrm{p}}=1.0 \mu \mathrm{m}$. The chemical half-life depended strongly on particle radius (i.e. number of oleic acid molecules contained in the particle). In the

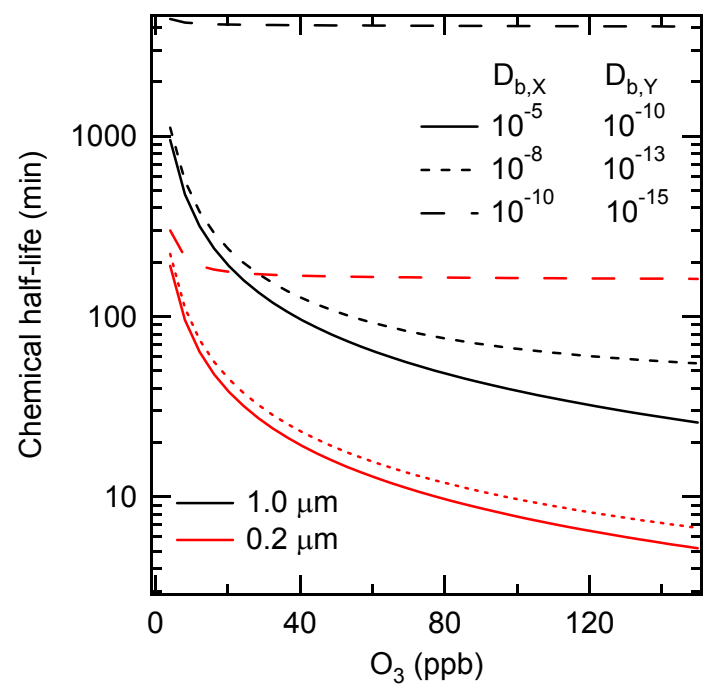

Fig. 11. Chemical half-life (min) of pure oleic acid particles with particle radius of 1.0 (black) and $0.2 \mu \mathrm{m}$ (red) as a function of gas phase $\mathrm{O}_{3}$ mixing ratio. The diffusion coefficients are $D_{\mathrm{b}, \mathrm{X}}=$ $10^{-5} \mathrm{~cm}^{2} \mathrm{~s}^{-1}, D_{\mathrm{b}, \mathrm{Y}}=10^{-10} \mathrm{~cm}^{2} \mathrm{~s}^{-1}$ (solid line, BC1), $D_{\mathrm{b}, \mathrm{X}}=$ $10^{-8} \mathrm{~cm}^{2} \mathrm{~s}^{-1}, D_{\mathrm{b}, \mathrm{Y}}=10^{-13} \mathrm{~cm}^{2} \mathrm{~s}^{-1}$ (dotted line), and $D_{\mathrm{b}, \mathrm{X}}=$ $10^{-10} \mathrm{~cm}^{2} \mathrm{~s}^{-1}, D_{\mathrm{b}, \mathrm{Y}}=10^{-15} \mathrm{~cm}^{2} \mathrm{~s}^{-1}$ (dashed line, BC3).

typical polluted air with $100 \mathrm{ppb} \mathrm{O}_{3}, t_{1 / 2}$ was shortened to $\sim 8 \mathrm{~min}$ for $r_{\mathrm{p}}=0.2 \mu \mathrm{m}$ and $\sim 40 \mathrm{~min}$ for $r_{\mathrm{p}}=1.0 \mu \mathrm{m}$. The calculations were also made in $\mathrm{BC} 2$, which gave almost the same results for $r_{\mathrm{p}}=0.2 \mu \mathrm{m}$ and gave $\sim 20 \%$ smaller value for $r_{\mathrm{p}}=1.0 \mu \mathrm{m}$ compared to BC1.

The ozonolysis of oleic acid leads to an increase of oxygen content and hygroscopicity (Asad et al., 2004), and it can convert CCN-inactive particles into CCN (King et al., 2009). Our model results suggest that the transformation of oleic acid particles will occur on a timescale of $\sim 1 \mathrm{~h}$ depending on atmospheric $\mathrm{O}_{3}$ concentration and particle size. This is in good agreement with the characteristic time of $1.3 \mathrm{~h}$ reported by King et al. (2009).

In spite of the short lifetimes found in laboratory experiments, however, oleic acid is detected also in aged atmospheric aerosol particles (Rogge et al., 1991; Morris et al., 2002). Possible explanations include reduced concentrations of $\mathrm{O}_{3}$ (and other photo-oxidants) in the particle bulk due to the following effects: (a) chemical reaction with other reactive species, self-reaction or catalytic decomposition; (b) competitive co-adsorption and surface reaction of multiple species such as water vapor and nitrogen oxides (Shiraiwa et al., 2009; Springmann et al., 2009); (c) slow mass transport because of low diffusion coefficients in solid or semisolid phases (crystalline, glassy, rubbery, gel-like or ultraviscous: Mikhailov et al., 2009). The formation of semisolid amorphous phases is generally favored by low temperature and low relative humidity (Zobrist et al., 2008), and it can occur in the core of atmospheric particles as well as 
in coatings formed by condensation of secondary particulate matter. For example, oligomerisation reactions may lead to high molecular mass, low hygroscopicity and low diffusivity of secondary organic coatings, effectively shutting off further ozonolysis and oxidation of oleic acid and other organic compounds in the bulk of coated particles.

The potential importance of the phase state of aerosol particles (solid, semi-solids, or liquid) for the ozonolysis of oleic acid was already pointed out by Knopf et al. (2005) and Zahardis and Petrucci (2007). To explore and quantify the effects and of kinetic limitation by bulk diffusion, we performed sensitivity studies with low diffusion coefficients that are characteristic for mass transport in highly viscous or semi-solid matrices (Bird et al., 2007; Swallen et al., 2007; Mikhailov et al., 2009).

The dotted lines in Fig. 11 show the effect of reducing the diffusion coefficients of $\mathrm{O}_{3}$ and oleic acid by three orders of magnitude $\left(D_{\mathrm{b}, \mathrm{X}}=10^{-8} \mathrm{~cm}^{2} \mathrm{~s}^{-1}, D_{\mathrm{b}, \mathrm{Y}}=10^{-13} \mathrm{~cm}^{2} \mathrm{~s}^{-1}\right)$. It increased $t_{1 / 2}$ by up to $\sim 100 \%$, depending on ozone concentration and particle diameter. The dashed lines shows the effect of reducing the diffusion coefficients to the same level as in the base case 3 presented and discussed above $\left(D_{\mathrm{b}, \mathrm{X}}=10^{-10} \mathrm{~cm}^{2} \mathrm{~s}^{-1}, D_{\mathrm{b}, \mathrm{Y}}=10^{-15} \mathrm{~cm}^{2} \mathrm{~s}^{-1}\right)$. In this case the chemical lifetimes increase by up to a factor of $\sim 100$ and become nearly independent of ozone concentration: $\sim 3 \mathrm{~h}$ for $r_{\mathrm{p}}=0.2 \mu \mathrm{m}$ and $\sim 3$ days for $r_{\mathrm{p}}=1.0 \mu \mathrm{m}$. The results confirm mass transport can have strong non-linear effects on the chemical aging of atmospheric aerosols, and that (semi-)solid matrices with low diffusion coefficients can effectively shield reactive organic compounds from degradation by atmospheric photo-oxidants.

\section{Conclusions}

We presented a novel kinetic multi-layer model (KM-SUB) that explicitly resolves all steps of mass transport and chemical reaction at the surface and in the bulk of aerosol particles. It includes adsorption and desorption, surface reactions and surface-bulk exchange as well as bulk diffusion and reaction.Unlike earlier models of aerosol chemistry (e.g., resistor model), the KM-SUB model approach does not require any simplifying assumptions about steady-state and mixing conditions. The temporal evolution of concentration profiles of volatile and non-volatile species in the particle bulk can be modeled along with surface concentrations and uptake coefficients.

The effects of bulk diffusion on the rate of gas uptake and particle transformation were explored for a popular reference system, the ozonolysis of oleic acid particles, assuming different diameters and different sets of kinetic parameters (surface accommodation coefficients, diffusion coefficients, etc.).

Under conditions where the reaction system was kinetically limited by interfacial transport or chemical reaction, the multi-layer model (KM-SUB) was in good agreement with a double-layer model (K2-SUB) using traditional resistor formulations for bulk processes. In case of kinetic limitation by bulk diffusion, however, the K2-SUB model overestimated the rates of gas uptake and oleic acid degradation, because it does not resolve and account for the concentration profile of oleic acid. Comparison with a partial differential equation (PDE) model confirmed the ability of KM-SUB to resolve diffusion and concentration profiles in the particle bulk.

We demonstrated and discussed how the KM-SUB model can be used to interpret and analyze experimental data from laboratory studies, and how the results can be extrapolated to atmospheric conditions. For liquid oleic acid particles, the chemical half-life of oleic acid molecules with regard to oxidation by ozone was estimated to of the order of one hour. In (semi-)solid particles with low bulk diffusivity, however, the chemical half-life can increase dramatically (up to multiple hours and days). The results of sensitivity studies with different bulk diffusion coefficients confirmed that the phase state of atmospheric particles is highly relevant for chemical transformation and aging (Knopf et al., 2005; McNeill et al., 2007, 2008; Zahardis and Petrucci, 2007; Griffiths et al., 2009; Mikhailov et al., 2009).

Depending on the complexity of the investigated system, unlimited numbers of volatile and non-volatile species and chemical reactions can be added flexibly. Thus, the KMSUB approach may serve as a basis for the development of a detailed master mechanism of aerosol chemistry and for the derivation of simplified but realistic parameterizations for large-scale atmospheric and climate models.

\section{Appendix A}

\section{List of Symbols}

\begin{tabular}{|c|c|c|}
\hline Symbol & Meaning & Unit \\
\hline$\alpha_{\mathrm{b}, \mathrm{X}_{i}}$ & $\begin{array}{l}\text { bulk accommodation coefficient } \\
\text { of } X_{i}\end{array}$ & \\
\hline$\alpha_{\mathrm{s}, \mathrm{X}_{i}}$ & $\begin{array}{l}\text { surface accommodation } \\
\text { coefficient of } X_{i}\end{array}$ & \\
\hline$\alpha_{\mathrm{s}, 0, \mathrm{X}_{i}}$ & $\begin{array}{l}\text { surface accommodation } \\
\text { coefficient of } \mathrm{X}_{i} \text { on an adsorbate- } \\
\text { free surface }\end{array}$ & \\
\hline$\alpha_{\mathrm{s}, 0, \mathrm{X}_{i}, \mathrm{Y}_{j}}$ & $\begin{array}{l}\text { surface accommodation } \\
\text { coefficient of } X_{i} \text { on an adsorbate- } \\
\text { free surface composed of } Y_{j}\end{array}$ & \\
\hline$\delta$ & thickness of bulk layers & $\mathrm{cm}$ \\
\hline$\delta_{\mathrm{X}_{i}}, \delta_{\mathrm{Y}_{j}}$ & $\begin{array}{l}\text { effective molecular diameter of } \\
\mathrm{X}_{i} \text { and } \mathrm{Y}_{j}\end{array}$ & $\mathrm{~cm}$ \\
\hline$\lambda \mathrm{X}_{i}$ & $\begin{array}{l}\text { mean free path of } X_{i} \text { in the gas } \\
\text { phase }\end{array}$ & $\mathrm{cm}$ \\
\hline
\end{tabular}




\begin{tabular}{|c|c|c|}
\hline Symbol & Meaning & Unit \\
\hline$\theta_{\mathrm{s}}$ & $\begin{array}{l}\text { sorption layer surface } \\
\text { coverage }\end{array}$ & \\
\hline$\theta_{\mathrm{ss}}$ & $\begin{array}{l}\text { quasi-static layer surface } \\
\text { coverage }\end{array}$ & \\
\hline$\sigma_{\mathrm{s}, \mathrm{X}_{i}}$ & $\begin{array}{l}\text { effective molecular cross } \\
\text { section of } \mathrm{X}_{i} \text { in the sorption } \\
\text { layer }\end{array}$ & $\mathrm{cm}^{2}$ \\
\hline$\gamma_{\mathrm{X}_{i}}$ & $\begin{array}{l}\text { uptake coefficient of } \mathrm{X}_{i} \\
\text { (normalized by gas kinetic } \\
\text { flux of surface collisions) }\end{array}$ & \\
\hline$\gamma_{\mathrm{gsr}, \mathrm{X}_{i}}$ & $\begin{array}{l}\text { reaction probability for el- } \\
\text { ementary gas-surface reac- } \\
\text { tions }\end{array}$ & \\
\hline$\tau_{\mathrm{d}, X_{i}}$ & desorption lifetime of $\mathrm{X}_{i}$ & $\mathrm{~s}$ \\
\hline$\tau_{\mathrm{d}, \mathrm{X}_{i}, \mathrm{Y}_{j}}$ & $\begin{array}{l}\text { desorption lifetime of } X_{i} \text { on } \\
\text { a surface composed of } Y_{j}\end{array}$ & $\mathrm{~s}$ \\
\hline$\Phi_{\mathrm{b}, \mathrm{Y} p}$ & $\begin{array}{l}\text { weighting factor (mole, } \\
\text { mass, or volume fraction of } \\
\mathrm{Y}_{p} \text { in the bulk) }\end{array}$ & \\
\hline$\omega \mathrm{X}_{i}$ & $\begin{array}{l}\text { mean thermal velocity of } \\
\mathrm{X}_{i} \text { in the gas phase }\end{array}$ & $\mathrm{cm} \mathrm{s}^{-1}$ \\
\hline$A(k)$ & $\begin{array}{l}\text { outer surface area of bulk } \\
\text { layer } k\end{array}$ & $\mathrm{~cm}^{2}$ \\
\hline$A_{\mathrm{ss}}$ & $\begin{array}{l}\text { surface area of particle } \\
\text { (quasi-static layer) }\end{array}$ & \\
\hline$c_{\mathrm{SLR} v, \mathrm{~s}, \mathrm{X}_{i}}$ & stoichiometric coefficients & \\
\hline$c_{\mathrm{SLR} v, \mathrm{ss}, \mathrm{Y}_{j}}$ & $\begin{array}{l}\text { of species } \mathrm{X}_{i} \text { and } \mathrm{Y}_{j} \text { in sur- } \\
\text { face layer reaction SLR } v\end{array}$ & \\
\hline$c_{\mathrm{BR} v, \mathrm{X}_{i},}$ & stoichiometric & \\
\hline$c_{\mathrm{BR} v, \mathrm{Y}_{j}}$ & $\begin{array}{l}\text { coefficients of species } X_{i} \\
\text { and } Y_{j} \text { in bulk reaction } \\
\mathrm{BR} v\end{array}$ & \\
\hline$C_{\mathrm{b}, \mathrm{rd}, \mathrm{X}_{i}}$ & $\begin{array}{l}\text { reacto-diffusive geometry } \\
\text { correction factor for } \mathrm{X}_{i}\end{array}$ & \\
\hline$C_{\mathrm{g}, \mathrm{X}_{i}}$ & $\begin{array}{l}\text { gas phase diffusion } \\
\text { correction factor for } \mathrm{X}_{i}\end{array}$ & \\
\hline $\begin{array}{l}D_{\mathrm{b}, \mathrm{X}_{i}} \\
D_{\mathrm{b}}\end{array}$ & $\begin{array}{l}\text { bulk diffusion coefficient of } \\
\mathrm{X}_{j} \text { and } \mathrm{Y}_{j}\end{array}$ & $\mathrm{~cm}^{2} \mathrm{~s}^{-1}$ \\
\hline $\begin{array}{l}J_{\mathrm{ads}, \mathrm{X}_{i}}, \\
J_{\mathrm{des}, \mathrm{X}_{i}}\end{array}$ & $\begin{array}{l}\text { flux of adsorption and des- } \\
\text { orption of } \mathrm{X}_{i}\end{array}$ & $\mathrm{~cm}^{-2} \mathrm{~s}^{-1}$ \\
\hline$J_{\mathrm{coll}, \mathrm{X}_{i}}$ & $\begin{array}{l}\text { flux of surface collisions of } \\
X_{i}\end{array}$ & $\mathrm{~cm}^{-2} \mathrm{~s}^{-1}$ \\
\hline $\begin{array}{l}J_{\mathrm{b}, \mathrm{rd}, \mathrm{X}_{i}} \\
J_{\mathrm{b}, \mathrm{s}, \mathrm{X}_{i}} \\
J_{\mathrm{b}, \mathrm{ss}, \mathrm{Y}_{j}}\end{array}$ & $\begin{array}{l}\text { reacto-diffusive flux of } \mathrm{X}_{i} \\
\text { flux of bulk-to- } \\
\text { surface transport of } \\
\mathrm{X}_{i} \text { (sorption layer) and } \\
\mathrm{Y}_{j} \text { (quasi-static layer) }\end{array}$ & $\begin{array}{l}\mathrm{cm}^{-2} \mathrm{~s}^{-1} \\
\mathrm{~cm}^{-2} \mathrm{~s}^{-1}\end{array}$ \\
\hline $\begin{array}{l}J_{\mathrm{s}, \mathrm{b}, \mathrm{X}_{i}} \\
J_{\mathrm{ss}, \mathrm{b}, \mathrm{Y}_{j}}\end{array}$ & $\begin{array}{l}\text { flux of surface-to- } \\
\text { bulktransport of } \\
\mathrm{X}_{i} \text { (sorption layer) and } \\
\mathrm{Y}_{j} \text { (quasi-static layer) }\end{array}$ & $\mathrm{cm}^{-1} \mathrm{~s}^{-1}$ \\
\hline
\end{tabular}

\begin{tabular}{|c|c|c|}
\hline Symbol & Meaning & Unit \\
\hline $\begin{array}{l}J_{\mathrm{b} k, \mathrm{~b} k-1, \mathrm{X}_{i}} \\
J_{\mathrm{b} k, \mathrm{~b} k-1, \mathrm{Y}_{j}}\end{array}$ & $\begin{array}{l}\text { flux of transport from bulk } \\
\text { layer } k \text { to bulk layer } k-1 \text { for } \mathrm{X}_{i} \\
\text { and } \mathrm{Y}_{j}\end{array}$ & $\mathrm{~cm}^{-2} \mathrm{~s}^{-1}$ \\
\hline $\begin{array}{l}k_{\mathrm{b}, \mathrm{b}, \mathrm{X}_{i}} \\
k_{\mathrm{b}, b, \mathrm{Y}_{j}}\end{array}$ & $\begin{array}{l}\text { rate coefficient (velocity) of } \\
\text { bulk transport of } X_{i} \text { and } Y_{j}\end{array}$ & $\mathrm{~cm} \mathrm{~s}^{-1}$ \\
\hline$k_{\mathrm{b}, \mathrm{s}, \mathrm{X}_{i}}$ & $\begin{array}{l}\text { rate coefficient (velocity) of } \\
\text { bulk-to-surface transport of } \\
\mathrm{X}_{i}\end{array}$ & $\mathrm{~cm} \mathrm{~s}^{-1}$ \\
\hline$k_{\mathrm{BR}, \mathrm{X}_{i}, \mathrm{Y}_{j}}$ & $\begin{array}{l}\text { second-order rate coefficients } \\
\text { for bulk reactions of } X_{i} \text { with } \\
Y_{j}\end{array}$ & $\mathrm{~cm}^{3} \mathrm{~s}^{-1}$ \\
\hline$k_{\mathrm{b}, \mathrm{ss}, \mathrm{Y}} i$ & $\begin{array}{l}\text { rate coefficient (velocity) of } \\
\text { bulk-to-surface transport of } \\
\mathrm{Y}_{j}\end{array}$ & $\mathrm{~cm} \mathrm{~s}^{-1}$ \\
\hline$k_{\mathrm{d}, \mathrm{X}_{i}}$ & $\begin{array}{l}\text { first-order desorption rate } \\
\text { coefficient of } X_{i}\end{array}$ & $\mathrm{~s}^{-1}$ \\
\hline$k_{\mathrm{s}, \mathrm{b}, \mathrm{X}_{i}}$ & $\begin{array}{l}\text { first-order rate coefficient for } \\
\text { surface-to-bulk transport of } \\
\mathrm{X}_{i}\end{array}$ & $\mathrm{~s}^{-1}$ \\
\hline$k_{\mathrm{ss}, \mathrm{b}, \mathrm{Y}_{j}}$ & $\begin{array}{l}\text { first-order rate coefficients for } \\
\text { surface-bulk transport of } Y_{j}\end{array}$ & $\mathrm{~s}^{-1}$ \\
\hline$k_{\mathrm{SLR}, \mathrm{X} p, \mathrm{Y} q}$ & $\begin{array}{l}\text { second-order rate coefficients } \\
\text { for surface layer reactions of } \\
\mathrm{X}_{p} \text { with } \mathrm{Y}_{q}\end{array}$ & $\mathrm{~cm}^{2} \mathrm{~s}^{-1}$ \\
\hline$K_{\mathrm{sol}, \mathrm{cc}, \mathrm{X}_{i}}$ & $\begin{array}{l}\text { gas-particle partitioning coef- } \\
\text { ficient of } \mathrm{X}_{i}\end{array}$ & \\
\hline$l_{\mathrm{rd}, \mathrm{X}_{i}}$ & $\begin{array}{l}\text { reacto-diffusive length of } \\
\mathrm{X}_{i} \text { and } \mathrm{Y}_{j}\end{array}$ & $\mathrm{~cm}^{-3} \mathrm{~s}^{-1}$ \\
\hline $\begin{array}{l}L_{\mathrm{b}, \mathrm{X}_{i}} \\
L_{\mathrm{b}, \mathrm{Y}_{j}}\end{array}$ & $\begin{array}{l}\text { loss rate of } X_{i} \text { and } Y_{j} \text { by } \\
\text { reaction in the particle bulk }\end{array}$ & $\mathrm{cm}^{-3} \mathrm{~s}^{-1}$ \\
\hline $\begin{array}{l}L_{\mathrm{b} k, X_{i}} \\
L_{\mathrm{b} k, \mathrm{Y}_{j}}\end{array}$ & $\begin{array}{l}\text { loss rate of } X_{i} \text { and } Y_{j} \text { by } \\
\text { reaction in bulk layer } k\end{array}$ & $\mathrm{~cm}^{-3} \mathrm{~s}^{-1}$ \\
\hline $\begin{array}{l}L_{\mathrm{s}, \mathrm{X}_{i}} \\
L_{\mathrm{ss}, \mathrm{Y}_{j}}\end{array}$ & $\begin{array}{l}\text { loss rate of } X_{i} \text { and } Y_{j} \text { by sur- } \\
\text { face layer reaction }\end{array}$ & $\mathrm{cm}^{-2} \mathrm{~s}^{-1}$ \\
\hline $\begin{array}{l}L_{\mathrm{b}, X_{i}}^{*} \\
L_{\mathrm{b}, Y_{j}}^{*}\end{array}$ & $\begin{array}{l}\text { absolute loss rate of } \mathrm{X}_{i} \text { and } \\
\mathrm{Y}_{j} \text { by reaction in the particle } \\
\text { bulk }\end{array}$ & $\mathrm{s}^{-1}$ \\
\hline $\begin{array}{l}L_{\mathrm{b} k, \mathrm{X}_{i}}^{*} \\
L_{\mathrm{b} k, \mathrm{Y}_{j}}^{*}\end{array}$ & $\begin{array}{l}\text { absolute loss rate of } \mathrm{X}_{i} \text { and } \\
\mathrm{Y}_{j} \text { by reaction in bulk layer } k\end{array}$ & $\mathrm{~s}^{-1}$ \\
\hline $\begin{array}{l}L_{\mathrm{s}, X_{i}}^{*} \\
L_{\mathrm{ss}, \mathrm{Y}_{j}}^{*}\end{array}$ & $\begin{array}{l}\text { absolute loss rate of } \mathrm{X}_{i} \text { and } \\
\mathrm{Y}_{j} \text { by surface layer reaction }\end{array}$ & $\mathrm{s}^{-1}$ \\
\hline$n$ & number of bulk layers & \\
\hline$N_{Y}$ & total number of Y molecules & \\
\hline $\begin{array}{l}P_{\mathrm{b}, \mathrm{X}_{i}} \\
P_{\mathrm{b}, \mathrm{Y}_{j}}\end{array}$ & $\begin{array}{l}\text { production rate of } X_{i} \text { and } Y_{j} \\
\text { by reaction in the particle bulk }\end{array}$ & $\mathrm{cm}^{-3} \mathrm{~s}^{-1}$ \\
\hline $\begin{array}{l}P_{\mathrm{b} k, \mathrm{X}_{i}} \\
P_{\mathrm{b} k, \mathrm{Y}_{j}}\end{array}$ & $\begin{array}{l}\text { production rate of } X_{i} \text { and } Y_{j} \\
\text { by reaction in bulk layer } k\end{array}$ & $\mathrm{~cm}^{-3} \mathrm{~s}^{-1}$ \\
\hline $\begin{array}{l}P_{\mathrm{s}, \mathrm{X}_{i}} \\
P_{\mathrm{ss}, \mathrm{Y}_{j}}\end{array}$ & $\begin{array}{l}\text { production rate of } X_{i} \text { and } Y_{j} \\
\text { by surface layer reaction }\end{array}$ & $\mathrm{cm}^{-2} \mathrm{~s}^{-1}$ \\
\hline$r_{\mathrm{b}}$ & particle bulk radius & $\mathrm{cm}$ \\
\hline$r_{\mathrm{p}}$ & particle radius & $\mathrm{cm}$ \\
\hline
\end{tabular}




\begin{tabular}{|c|c|c|}
\hline Symbol & Meaning & Unit \\
\hline$\left[\mathrm{X}_{i}\right]_{\mathrm{g}}$ & $\begin{array}{l}\text { gas phase number concentration } \\
\text { of } X_{i}\end{array}$ & $\mathrm{~cm}^{-3}$ \\
\hline$\left[\mathrm{X}_{i}\right]_{\mathrm{gs}}$ & $\begin{array}{l}\text { Near-surface gas phase number } \\
\text { concentration of } X_{i}\end{array}$ & $\mathrm{~cm}^{-3}$ \\
\hline$\left[\mathrm{X}_{i}\right]_{\mathrm{S}}$ & $\begin{array}{l}\text { surface number concentration of } \\
\mathrm{X}_{i} \text { (sorption layer) }\end{array}$ & $\mathrm{cm}^{-2}$ \\
\hline$\left[\mathrm{Y}_{j}\right]_{\mathrm{ss}}$ & $\begin{array}{l}\text { surface number concentration of } \\
\mathrm{Y}_{j} \text { (quasi-static layer) }\end{array}$ & $\mathrm{cm}^{-2}$ \\
\hline$\left[\mathrm{X}_{i}\right]_{\mathrm{b} k},\left[\mathrm{Y}_{j}\right]_{\mathrm{b} k}$ & $\begin{array}{l}\text { Bulk number concentration of } \\
\mathrm{X}_{i} \text { and } \mathrm{Y}_{j} \text { in the bulk layer } k\end{array}$ & $\mathrm{~cm}^{-3}$ \\
\hline$V_{\mathrm{b}}$ & volume of particle bulk & \\
\hline$V(k)$ & volume of bulk layer $k$ & $\mathrm{~cm}^{-3}$ \\
\hline
\end{tabular}

\section{Appendix B}

\section{Partial differential equation model (PDE)}

Smith et al. (2003) demonstrated that the diffusion and reaction in the bulk can be described by the following partial differential equations:

$$
\begin{aligned}
& \frac{\partial[\mathrm{X}]_{\mathrm{b}}}{\partial t}=\frac{D_{\mathrm{b}, \mathrm{X}}}{r^{2}} \frac{\partial}{\partial r}\left(r^{2} \frac{\partial[\mathrm{X}]_{\mathrm{b}}}{\partial r}\right)-k_{\mathrm{BR}, \mathrm{X}, \mathrm{Y}}[\mathrm{X}]_{\mathrm{b}}[\mathrm{Y}]_{\mathrm{b}} \\
& \frac{\partial[\mathrm{Y}]_{\mathrm{b}}}{\partial t}=\frac{D_{\mathrm{b}, \mathrm{Y}}}{r^{2}} \frac{\partial}{\partial r}\left(r^{2} \frac{\partial[\mathrm{Y}]_{\mathrm{b}}}{\partial r}\right)-k_{\mathrm{BR}, \mathrm{X}, \mathrm{Y}}[\mathrm{X}]_{\mathrm{b}}[\mathrm{Y}]_{\mathrm{b}}
\end{aligned}
$$

where $\mathrm{X}=\mathrm{O}_{3}$ and $\mathrm{Y}=\mathrm{oleic}$ acid. The first term describes diffusion based on the Fick's law and the second term describes chemical reaction in the bulk. Note that this partial differential equation (PDE) method can only simulate the processes in the bulk and not coupled with surface processes. In solving these PDE equations, several assumptions are required as boundary conditions (Smith et al., 2003): (1) The concentration of the near-surface bulk is fixed over time, (2) the flux of $\mathrm{X}$ at the core is zero $\left(\partial[\mathrm{X}]_{\mathrm{b}} /\left.\partial r\right|_{r=0}=0\right)$, (3) the flux of $\mathrm{Y}$ at both near-surface bulk and core is zero $\left(\partial[\mathrm{X}]_{\mathrm{b}} /\left.\partial r\right|_{r=r_{\mathrm{p}}}=\partial[\mathrm{X}]_{\mathrm{b}} /\left.\partial r\right|_{r=0}=0\right)$. PDE model simulations were performed by numerically solving the partial differential equations with Matlab software (PDEPE solver).

We investigate large particles with a radius of $1.0 \mu \mathrm{m}$ as investigated by Smith et al. (2003), and we compare the KM-SUB results $(n=200)$ to the results of the PDE model. The gas phase ozone concentration was set to $[\mathrm{X}]_{\mathrm{g}}=[\mathrm{X}]_{\mathrm{gs}}=$ $7.0 \times 10^{13} \mathrm{~cm}^{-3}$ (corresponding to $2.8 \mathrm{ppm}$ at $1013 \mathrm{hPa}$ and $298 \mathrm{~K}$ ). The initial surface and bulk concentrations of ozone (X) were set to $[\mathrm{X}]_{\mathrm{s}, 0}=[\mathrm{X}]_{\mathrm{b} k, 0}=0$, and the initial surface and bulk concentrations of oleic acid $(\mathrm{Y})$ were set to $[\mathrm{Y}]_{\mathrm{ss}, 0}=9.7 \times 10^{13} \mathrm{~cm}^{-2}$ and $[\mathrm{Y}]_{\mathrm{ss}, 0}=1.2 \times 10^{21} \mathrm{~cm}^{-3}$, respectively. The kinetic parameters used are based on base case 1 summarized in Table 1 with the second-order surface reaction rate coefficient $\left(k_{\mathrm{SLR}, \mathrm{X}, \mathrm{Y}}\right)$ of zero. Unlike
KM-SUB, the PDE model depends on the assumption of a fixed ozone concentration in the near surface bulk. Smith et al. (2003) had assumed solubility saturation according to Henry's law. In case of fast reaction, however, chemical loss leads to a substantial decrease and lower value of the actual ozone concentration. For comparability, the concentration of ozone in the near-surface bulk of the PDE model was set to a value of $5.0 \times 10^{13} \mathrm{~cm}^{-3}$, which is similar to the value calculated by KM-SUB.

Figure A1 shows the concentration profiles of ozone (top) and oleic acid (bottom) obtained by simulations with KMSUB (left) and with the PDE model (right). The diffusion of $\mathrm{O}_{3}$ into the bulk was very slow due to the large particle diameter, so that there was a large concentration gradient of $\mathrm{O}_{3}$. The concentration of $\mathrm{O}_{3}$ at the core remains small $\left(<10^{3} \mathrm{~cm}^{-3}\right)$ over the reaction time considered. Oleic acid showed also a concentration gradient, which was due to the $\mathrm{O}_{3}$ concentration gradient and a slow diffusion coefficient of oleic acid $\left(D_{\mathrm{b}, \mathrm{Y}}=10^{-10} \mathrm{~cm}^{2} \mathrm{~s}^{-1}\right)$. If a larger $D_{\mathrm{b}, \mathrm{Y}}$ of $10^{-7} \mathrm{~cm}^{2} \mathrm{~s}^{-1}$ was used in the simulation, the concentration of oleic acid was homogeneous throughout the bulk, which was consistent with the results reported by Smith et al. (2003).

The KM-SUB and PDE methods yield very similar results, but the concentration gradients for both $\mathrm{O}_{3}$ and oleic acid were slightly steeper in the PDE model. A possible reason for the difference may be that the PDE model requires the assumption of a fixed ozone concentration in the near surface bulk and zero flux values at the surface and at center of the particles as specified above (boundary conditions). Another possible reason for deviations is the estimation of bulk transport velocities $\left(k_{\mathrm{b}, \mathrm{b}}\right)$. If we assume $k_{\mathrm{b}, \mathrm{b}}=D_{\mathrm{b}} / \delta$ instead of Eqs. (35) and (36), the KM-SUB results become nearly identical to the PDE results. Note that varying the number of layers in the KM-SUB model made practically no difference.

\section{Appendix C}

\section{Kinetic double-layer model (K2-SUB)}

A kinetic double-layer of surface and bulk chemistry (K2SUB) was developed by Pfrang et al. (2009). K2-SUB uses one layer for bulk, therefore concentration profiles in the bulk is not obtained. The diffusion and reaction in the bulk is considered by the reacto-diffusive flux $\left(J_{\mathrm{b}, \mathrm{rd}}\right)$ (Danckwerts, 1951; Hanson, 1997; Pöschl et al., 2007). The loss rate of oleic acid in the bulk can be described as follows (Pfrang et al., 2009), which is based on the resistor model formulation (Hanson, 1997):

$$
\begin{aligned}
& L_{\mathrm{b}, \mathrm{Y}}=J_{\mathrm{b}, \mathrm{rd}, \mathrm{X}} \frac{A_{\mathrm{ss}}}{V_{\mathrm{b}}} \\
& =C_{\mathrm{b}, \mathrm{rd}, \mathrm{X}} \sqrt{k_{\mathrm{BR}, \mathrm{X}, \mathrm{Y}}[\mathrm{Y}]_{\mathrm{b}} D_{\mathrm{b}, \mathrm{X}}}[\mathrm{X}]_{\mathrm{bs}} \frac{A_{\mathrm{ss}}}{V_{\mathrm{b}}}
\end{aligned}
$$



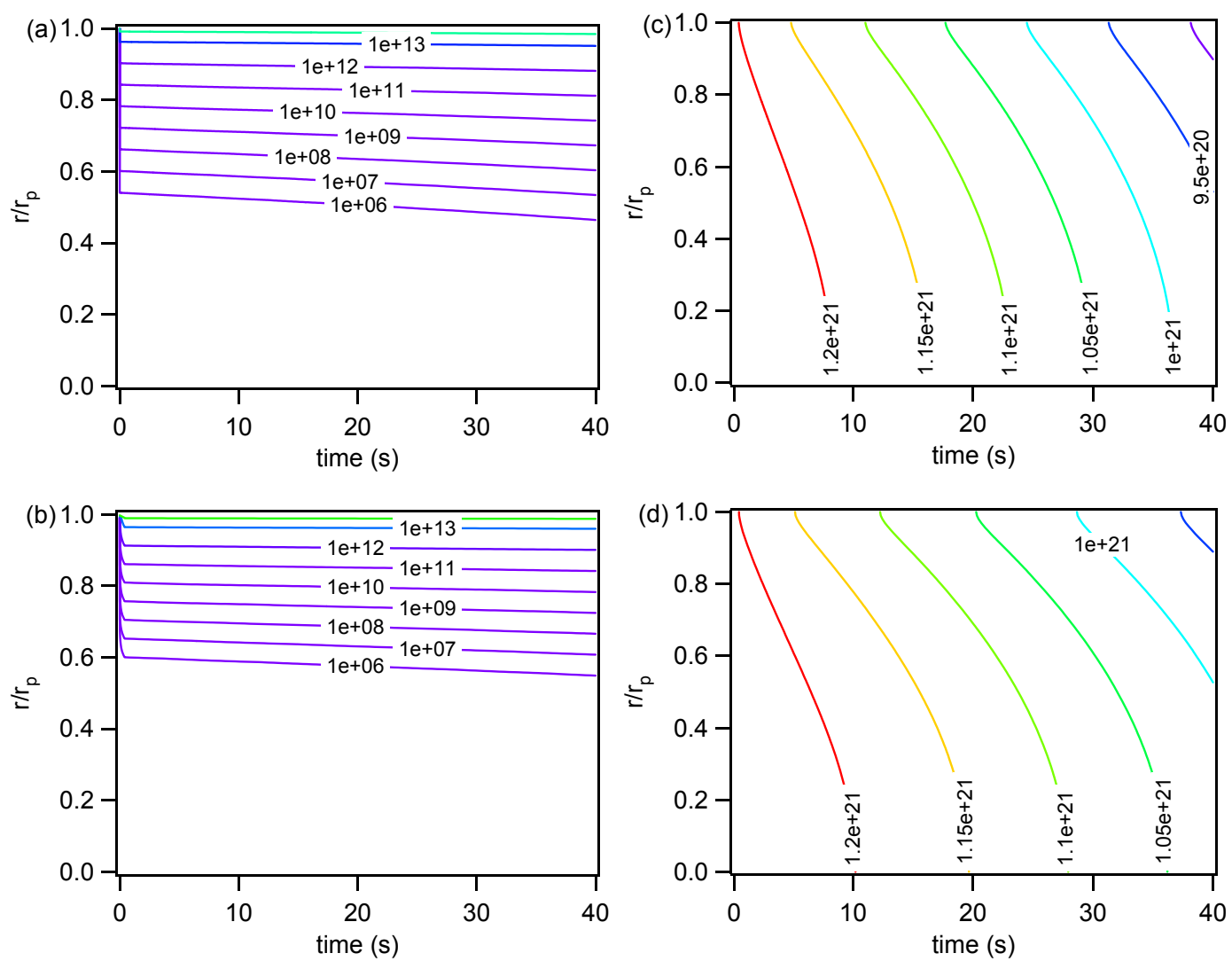

Fig. A1. Temporal evolution of bulk concentration profiles for ozone by (a) KM-SUB and (b) PDE method and for oleic acid by (c) KM-SUB and (d) PDE method. The y-axis indicates the radial distance from the particle center $(r)$ normalized by the particle radius, ranging from the particle core $\left(r / r_{\mathrm{p}} \approx 0\right)$ to the near-surface bulk $\left(r / r_{\mathrm{p}}=1\right)$. The colored lines are isopleths of bulk concentration with labeled in units of $\mathrm{cm}^{-3}$ (blue $=$ low, red $=$ high).

where $A_{\mathrm{ss}}$ and $V_{\mathrm{b}}$ is the surface area and volume of bulk particle. $C_{\mathrm{b}, \mathrm{rd}, \mathrm{X}}$ is the reacto-diffusive geometry correction factor (conversion from planar to spherical geometry) (Pöschl et al., 2007). $C_{\mathrm{b}, \mathrm{rd}, \mathrm{X}}$ is a function of particle radius $\left(r_{\mathrm{p}}\right)$ and the reacto-diffusive length $l_{\mathrm{rd}, \mathrm{X}}$, which can be regarded as the distance from the surface up to which the chemical reaction proceeds effectively (Finlayson-Pitts and Pitts, 2000; Pöschl et al., 2007):

$$
C_{\mathrm{b}, \mathrm{rd}, \mathrm{X}}=\operatorname{coth}\left(\frac{r_{\mathrm{p}}}{l_{\mathrm{rd}, \mathrm{X}}}\right)-\frac{l_{\mathrm{rd}, \mathrm{X}}}{r_{\mathrm{p}}}
$$

$l_{\mathrm{rd}, \mathrm{X}}=\sqrt{D_{\mathrm{b}, \mathrm{X}} /\left(k_{\mathrm{BR}, \mathrm{X}, \mathrm{Y}}[\mathrm{Y}]_{\mathrm{b}}\right)}$

K2-SUB presented by Pfrang et al. (2009) assumed the steady-state condition of $\mathrm{O}_{3}$ in surface and bulk. K2-SUB was modified by removing these assumptions by including the gas-surface interaction fluxes (adsorption $\left(J_{\mathrm{ads}, \mathrm{X}}\right)$, desorption $\left(J_{\mathrm{des}, \mathrm{X}}\right)$ and surface layer reaction $\left(L_{\mathrm{s}, \mathrm{X}}\right.$ and $\left.\left.L_{\mathrm{ss}, \mathrm{X}}\right)\right)$ in the differential equations $\left(\mathrm{X}=\mathrm{O}_{3}, \mathrm{Y}=\right.$ oleic acid). The differential equations below can be solved using Matlab solver.

$\mathrm{d}[\mathrm{X}]_{\mathrm{s}} / \mathrm{d} t=J_{\mathrm{ads}, \mathrm{X}}-J_{\mathrm{des}, \mathrm{X}}-L_{\mathrm{s}, \mathrm{X}}-J_{\mathrm{s}, \mathrm{b}, \mathrm{X}}+J_{\mathrm{b}, \mathrm{s}, \mathrm{X}}$

$$
\begin{aligned}
& \mathrm{d}[\mathrm{Y}]_{\mathrm{ss}} / \mathrm{d} t=J_{\mathrm{b}, \mathrm{ss}, \mathrm{Y}}-J_{\mathrm{ss}, \mathrm{b}, \mathrm{Y}}-L_{\mathrm{ss}, \mathrm{Y}} \\
& \mathrm{d}[\mathrm{X}]_{\mathrm{b}} / \mathrm{d} t=\left(J_{\mathrm{s}, \mathrm{b}, \mathrm{X}}-J_{\mathrm{b}, \mathrm{s}, \mathrm{X}}-J_{\mathrm{b}, \mathrm{rd}, \mathrm{X}}\right) A_{\mathrm{ss}} / V_{\mathrm{b}} \\
& \mathrm{d}[\mathrm{Y}]_{\mathrm{b}} / \mathrm{d} t=\left(J_{\mathrm{ss}, \mathrm{b}, \mathrm{Y}}-J_{\mathrm{b}, \mathrm{ss}, \mathrm{Y}}-J_{\mathrm{b}, \mathrm{rd}, \mathrm{X}}\right) A_{\mathrm{ss}} / V_{\mathrm{b}}
\end{aligned}
$$

\section{Appendix D}

\section{KM-SUB rate equations for the ozone - oleic acid model system}

The general rate equations outlined in the main text of this manuscript can be applied to any system with multiple chemical components and reactions. The equations actually needed to model the simple two-component system of ozone $(\mathrm{X})$ and oleic acid $(\mathrm{Y})$ investigated in this study are more compact as specified below:

$$
\begin{aligned}
& \mathrm{d}[\mathrm{X}]_{\mathrm{s}} / \mathrm{d} t=\alpha_{\mathrm{s}, 0, \mathrm{X}}\left(1-\theta_{\mathrm{s}}\right)[\mathrm{X}]_{\mathrm{gs}} \omega_{\mathrm{X}} / 4-\tau_{\mathrm{d}, \mathrm{X}}^{-1}[\mathrm{X}]_{\mathrm{s}} \\
& -k_{\mathrm{SLR}, \mathrm{X}, \mathrm{Y}}[\mathrm{X}]_{\mathrm{s}}[\mathrm{Y}]_{\mathrm{ss}}-k_{\mathrm{s}, \mathrm{b}, \mathrm{X}}[\mathrm{X}]_{\mathrm{s}}+k_{\mathrm{b}, \mathrm{s}, \mathrm{X}}[\mathrm{X}]_{\mathrm{b} 1}
\end{aligned}
$$


$\mathrm{d}[\mathrm{Y}]_{\mathrm{ss}} / \mathrm{d} t=k_{\mathrm{b}, \mathrm{ss}, \mathrm{Y}}[\mathrm{Y}]_{\mathrm{b} 1}-k_{\mathrm{ss}, \mathrm{b}, \mathrm{Y}}[\mathrm{Y}]_{\mathrm{ss}}$

$-k_{\mathrm{SLR}, \mathrm{X}, \mathrm{Y}}[\mathrm{X}]_{\mathrm{S}}[\mathrm{Y}]_{\mathrm{ss}}$

$$
\begin{aligned}
& \mathrm{d}[\mathrm{X}]_{\mathrm{b} 1} / \mathrm{d} t=\left(k_{\mathrm{s}, \mathrm{b}, \mathrm{X}}[\mathrm{X}]_{\mathrm{s}}-k_{\mathrm{b}, \mathrm{s}, \mathrm{X}}[\mathrm{X}]_{\mathrm{b} 1}\right) A(1) / V(1) \\
& -\left(k_{\mathrm{b}, \mathrm{b}, \mathrm{X}}[\mathrm{X}]_{\mathrm{b} 1}-k_{\mathrm{b}, \mathrm{b}, \mathrm{X}}[\mathrm{X}]_{\mathrm{b} 2}\right) A(2) / V(1) \\
& -k_{\mathrm{BR}, \mathrm{X}, \mathrm{Y}}[\mathrm{X}]_{\mathrm{b} 1}[\mathrm{Y}]_{\mathrm{b} 1}
\end{aligned}
$$

$$
\begin{aligned}
& \mathrm{d}[\mathrm{Y}]_{\mathrm{b} 1} / \mathrm{d} t=\left(k_{\mathrm{ss}, \mathrm{b}, \mathrm{Y}}[\mathrm{Y}]_{\mathrm{ss}}-k_{\mathrm{b}, \mathrm{ss}, \mathrm{Y}}[\mathrm{Y}]_{\mathrm{b} 1}\right) A(1) / V(1) \\
& -\left(k_{\mathrm{b}, \mathrm{b}, \mathrm{Y}}[\mathrm{Y}]_{\mathrm{b} 1}-k_{\mathrm{b}, \mathrm{b}, \mathrm{Y}}[\mathrm{Y}]_{\mathrm{b} 2}\right) A(2) / V(1) \\
& -k_{\mathrm{BR}, \mathrm{X}, \mathrm{Y}}[\mathrm{X}]_{\mathrm{b} 1}[\mathrm{Y}]_{\mathrm{b} 1}
\end{aligned}
$$

$$
\begin{aligned}
& \mathrm{d}[\mathrm{X}]_{\mathrm{b} k} / \mathrm{d} t=\left(k_{\mathrm{b}, \mathrm{b}, \mathrm{X}}[\mathrm{X}]_{\mathrm{b} k-1}-k_{\mathrm{b}, \mathrm{b}, \mathrm{X}}[\mathrm{X}]_{\mathrm{b} k}\right) A(k) / V(k) \\
& -\left(k_{\mathrm{b}, \mathrm{b}, \mathrm{X}}[\mathrm{X}]_{\mathrm{b} k}-k_{\mathrm{b}, \mathrm{b}, \mathrm{X}}[\mathrm{X}]_{\mathrm{b} k+1}\right) A(k+1) / V(k) \\
& -k_{\mathrm{BR}, \mathrm{X}, \mathrm{Y}}[\mathrm{X}]_{\mathrm{b} k}[\mathrm{Y}]_{\mathrm{b} k} \quad(k=2, \ldots, n-1)
\end{aligned}
$$

$$
\begin{aligned}
& \mathrm{d}[\mathrm{Y}]_{\mathrm{b} k} / \mathrm{d} t=\left(k_{\mathrm{b}, \mathrm{b}, \mathrm{Y}}[\mathrm{Y}]_{\mathrm{b} k-1}-k_{\mathrm{b}, \mathrm{b}, \mathrm{Y}}[\mathrm{Y}]_{\mathrm{b} k}\right) A(k) / V(k) \\
& -\left(k_{\mathrm{b}, \mathrm{b}, \mathrm{Y}}[\mathrm{Y}]_{\mathrm{b} k}-k_{\mathrm{b}, \mathrm{b}, \mathrm{Y}}[\mathrm{Y}]_{\mathrm{b} k+1}\right) A(k+1) / V(k) \\
& -k_{\mathrm{BR}, \mathrm{X}, \mathrm{Y}}[\mathrm{X}]_{\mathrm{b} k}[\mathrm{Y}]_{\mathrm{b} k} \quad(k=2, \ldots, n-1)
\end{aligned}
$$

$\mathrm{d}[\mathrm{X}]_{\mathrm{b} n} / \mathrm{d} t=\left(k_{\mathrm{b}, \mathrm{b}, \mathrm{X}}[\mathrm{X}]_{\mathrm{b} n-1}-k_{\mathrm{b}, \mathrm{b}, \mathrm{X}}[\mathrm{X}]_{\mathrm{b} n}\right) A(n) / V(n)$

$-k_{\mathrm{BR}, \mathrm{X}, \mathrm{Y}}[\mathrm{X}]_{\mathrm{b} n}[\mathrm{Y}]_{\mathrm{b} n}$

$$
\begin{aligned}
& \mathrm{d}[\mathrm{Y}]_{\mathrm{b} n} / \mathrm{d} t=\left(k_{\mathrm{b}, \mathrm{b}, \mathrm{Y}}[\mathrm{Y}]_{\mathrm{b} n-1}-k_{\mathrm{b}, \mathrm{b}, \mathrm{Y}}[\mathrm{Y}]_{\mathrm{b} n}\right) A(n) / V(n) \\
& -k_{\mathrm{BR}, \mathrm{X}, \mathrm{Y}}[\mathrm{X}]_{\mathrm{b} n}[\mathrm{Y}]_{\mathrm{b} n}
\end{aligned}
$$

Acknowledgements. This work was funded by the Max Planck Society (MPG) and the European integrated project on cloud climate and air quality interactions (No 036833-2 EUCAARI). MS is supported by the Max Planck Graduate Center (MPGC) and the Ministry of Education, Culture, Sports, Science and Technology - Japan (MEXT). CP wishes to thank the Royal Society (grant VO080001) and the NERC (grant NE/G000883/1). We acknowledge M. Ammann for stimulating discussions and two anonymous referees for constructive comments and suggestions.

The service charges for this open access publication have been covered by the Max Planck Society.

Edited by: V.-M. Kerminen

\section{References}

Ammann, M., Kalberer, M., Jost, D. T., Tobler, L., Rossler, E., Piguet, D., Gäggeler, H. W., and Baltensperger, U.: Heterogeneous production of nitrous acid on soot in polluted air masses, Nature, 395, 157-160, 1998.

Ammann, M. and Pöschl, U.: Kinetic model framework for aerosol and cloud surface chemistry and gas-particle interactions - Part 2: Exemplary practical applications and numerical simulations, Atmos. Chem. Phys., 7, 6025-6045, 2007, http://www.atmos-chem-phys.net/7/6025/2007/.

Andreae, M. O. and Rosenfeld, D.: Aerosol-cloud-precipitation interactions, Part 1. The nature and sources of cloud-active aerosols, Earth-Sci. Rev., 89, 13-41, 2008.

Anttila, T., Kiendler-Scharr, A., Tillmann, R., and Mentel, T. F.: On the reactive uptake of gaseous compounds by organic-coated aqueous aerosols: Theoretical analysis and application to the heterogeneous hydrolysis of $\mathrm{N}_{2} \mathrm{O}_{5}$, J. Phys. Chem. A., 110, 1043510443, 2006.

Asad, A., Mmereki, B. T., and Donaldson, D. J.: Enhanced uptake of water by oxidatively processed oleic acid, Atmos. Chem. Phys., 4, 2083-2089, 2004,

http://www.atmos-chem-phys.net/4/2083/2004/.

Atkins, P. W.: Physical Chemistry, Oxford University Press, Oxford, 1998.

Bird, R. B., Stewart, W. E., and Lightfoot, E. N.: Transport Phenomena (2nd Ed.), John Wiley \& Sons, Inc., New York, 2007.

Danckwerts, P. V.: Absorption by simultaneous diffusion and chemical reaction into particles of various shapes and into falling drops, Transactions of the Faraday Society, 47, 1014-1023, 1951.

Finlayson-Pitts, B. J. and Pitts, J. N.: Chemistry of the upper and lower atmosphere, San Diego, California, Academic Pres, 2000.

Fuzzi, S., Andreae, M. O., Huebert, B. J., Kulmala, M., Bond, T. C., Boy, M., Doherty, S. J., Guenther, A., Kanakidou, M., Kawamura, K., Kerminen, V.-M., Lohmann, U., Russell, L. M., and Pöschl, U.: Critical assessment of the current state of scientific knowledge, terminology, and research needs concerning the role of organic aerosols in the atmosphere, climate, and global change, Atmos. Chem. Phys., 6, 2017-2038, 2006, http://www.atmos-chem-phys.net/6/2017/2006/.

Gonzalez-Labrada, E., Schmidt, R., and DeWolf, C. E.: Kinetic analysis of the ozone processing of an unsaturated organic monolayer as a model of an aerosol surface, Phys. Chem. Chem. Phys., 9, 5814-5821, 2007.

Griffiths, P. T., Badger, C. L., Cox, R. A., Folkers, M., Henk, H. H., and Mentel, T. F.: Reactive Uptake of $\mathrm{N}_{2} \mathrm{O}_{5}$ by Aerosols Containing Dicarboxylic Acids. Effect of Particle Phase, Composition, and Nitrate Content, J. Phys. Chem. A., 113, 5082-5090, 2009.

Hallquist, M., Wenger, J. C., Baltensperger, U., Rudich, Y., Simpson, D., Claeys, M., Dommen, J., Donahue, N. M., George, C., Goldstein, A. H., Hamilton, J. F., Herrmann, H., Hoffmann, T., Iinuma, Y., Jang, M., Jenkin, M. E., Jimenez, J. L., Kiendler-Scharr, A., Maenhaut, W., McFiggans, G., Mentel, Th. F., Monod, A., Prévôt, A. S. H., Seinfeld, J. H., Surratt, J. D., Szmigielski, R., and Wildt, J.: The formation, properties and impact of secondary organic aerosol: current and emerging issues, Atmos. Chem. Phys., 9, 5155-5236, 2009, http://www.atmos-chem-phys.net/9/5155/2009/. 
Hanson, D. R.: Surface-specific reactions on liquids, J. Phys. Chem. B., 101, 4998-5001, 1997.

Hearn, J. D., Lovett, A. J., and Smith, G. D.: Ozonolysis of oleic acid particles: evidence for a surface reaction and secondary reactions involving Criegee intermediates, Phys. Chem. Chem. Phys., 7, 501-511, 2005.

Hearn, J. D. and Smith, G. A.: Ozonolysis of mixed oleic acid/n-docosane particles: The roles of phase, morphology, and metastable states, J. Phys. Chem. A., 111, 11059-11065, 2007.

Jimenez, J. L., Canagaratna, M. R., Donahue, N. M., Prevot, A. S. H., Zhang, Q., Kroll, J. H., DeCarlo, P. F., Allan, J. D., Coe, H., Ng, N. L., Aiken, A. C., Docherty, K. S., Ulbrich, I. M., Grieshop, A. P., Robinson, A. L., Duplissy, J., Smith, J. D., Wilson, K. R., Lanz, V. A., Hueglin, C., Sun, Y. L., Tian, J., Laaksonen, A., Raatikainen, T., Rautiainen, J., Vaattovaara, P., Ehn, M., Kulmala, M., Tomlinson, J. M., Collins, D. R., Cubison, M. J., Dunlea, E. J., Huffman, J. A., Onasch, T. B., Alfarra, M. R., Williams, P. I., Bower, K., Kondo, Y., Schneider, J., Drewnick, F., Borrmann, S., Weimer, S., Demerjian, K., Salcedo, D., Cottrell, L., Griffin, R., Takami, A., Miyoshi, T., Hatakeyama, S., Shimono, A., Sun, J. Y., Zhang, Y. M., Dzepina, K., Kimmel, J. R., Sueper, D., Jayne, J. T., Herndon, S. C., Trimborn, A. M., Williams, L. R., Wood, E. C., Middlebrook, A. M., Kolb, C. E., Baltensperger, U., and Worsnop, D. R.: Evolution of Organic Aerosols in the Atmosphere, Science, 326, 1525-1529, 2009.

Kanakidou, M., Seinfeld, J. H., Pandis, S. N., Barnes, I., Dentener, F. J., Facchini, M. C., Van Dingenen, R., Ervens, B., Nenes, A., Nielsen, C. J., Swietlicki, E., Putaud, J. P., Balkanski, Y., Fuzzi, S., Horth, J., Moortgat, G. K., Winterhalter, R., Myhre, C. E. L., Tsigaridis, K., Vignati, E., Stephanou, E. G., and Wilson, J.: Organic aerosol and global climate modelling: a review, Atmos. Chem. Phys., 5, 1053-1123, 2005,

http://www.atmos-chem-phys.net/5/1053/2005/.

Katrib, Y., Martin, S. T., Hung, H. M., Rudich, Y., Zhang, H. Z., Slowik, J. G., Davidovits, P., Jayne, J. T., and Worsnop, D. R.: Products and mechanisms of ozone reactions with oleic acid for aerosol particles having core-shell morphologies, J. Phys. Chem. A., 108, 6686-6695, 2004.

Katrib, Y., Biskos, G., Buseck, P. R., Davidovits, P., Jayne, J. T., Mochida, M., Wise, M. E., Worsnop, D. R., and Martin, S. T.: Ozonolysis of mixed oleic-acid/stearic-acid particles: Reaction kinetics and chemical morphology, J. Phys. Chem. A., 109, 10910-10919, 2005.

King, M. D., Thompson, K. C., and Ward, A. D.: Laser tweezers Raman study of optically trapped aerosol droplets of Seawater and oleic acid reacting with ozone: Implications for clouddroplet properties J. Am. Chem. Soc., 126, 16710-16711, 2004.

King, M. D., Thompson, K. C., Ward, A. D., Pfrang, C., and Hughes, B. R.: Oxidation of biogenic and water-soluble compounds in aqueous and organic aerosol droplets by ozone: a kinetic and product analysis approach using laser Raman tweezers, Faraday Discuss., 137, 173-192, 2008.

King, M. D., Rennie, A. R., Thompson, K. C., Fisher, F. N., Dong, C. C., Thomas, R. K., Pfrang, C., and Hughes, A. V.: Oxidation of oleic acid at the air-water interface and its potential effects on cloud critical supersaturations, Phys. Chem. Chem. Phys., 11, 7699-7707, 2009.

Knopf, D. A., Anthony, L. M., and Bertram, A. K.: Reactive uptake of $\mathrm{O}_{3}$ by multicomponent and multiphase mixtures containing oleic acid, J. Phys. Chem. A., 109, 5579-5589, 2005.

McNeill, V. F., Wolfe, G. M., and Thornton, J. A.: The oxidation of oleate in submicron aqueous salt aerosols: Evidence of a surface process, J. Phys. Chem. A., 111, 1073-1083, 2007.

McNeill, V. F., Yatavelli, R. L. N., Thornton, J. A., Stipe, C. B., and Landgrebe, $\mathrm{O}$.: Heterogeneous $\mathrm{OH}$ oxidation of palmitic acid in single component and internally mixed aerosol particles: vaporization and the role of particle phase, Atmos. Chem. Phys., 8, 5465-5476, 2008,

http://www.atmos-chem-phys.net/8/5465/2008/.

Mikhailov, E., Vlasenko, S., Martin, S. T., Koop, T., and Pöschl, U.: Amorphous and crystalline aerosol particles interacting with water vapor: conceptual framework and experimental evidence for restructuring, phase transitions and kinetic limitations, Atmos. Chem. Phys., 9, 9491-9522, 2009,

http://www.atmos-chem-phys.net/9/9491/2009/.

Moise, T. and Rudich, Y.: Reactive uptake of ozone by proxies for organic aerosols: Surface versus bulk processes, J. Geophys. Res.-Atmos., 105, 14667-14676, 2000.

Moise, T. and Rudich, Y.: Reactive uptake of ozone by aerosolassociated unsaturated fatty acids: Kinetics, mechanism, and products, J. Phys. Chem. A., 106, 6469-6476, 2002.

Morris, J. W., Davidovits, P., Jayne, J. T., Jimenez, J. L., Shi, Q., Kolb, C. E., Worsnop, D. R., Barney, W. S., and Cass, G.: Kinetics of submicron oleic acid aerosols with ozone: a novel aerosol mass spectrometric technique, Geophys. Res. Lett., 29, 1357, doi:10.1029/2002g1014692, 2002.

Pfrang, C., Shiraiwa, M., and Pöschl, U.: Coupling aerosol surface and bulk chemistry with a kinetic double layer model (K2-SUB): oxidation of oleic acid by ozone, Atmos. Chem. Phys. Discuss., 9, 26969-27019, 2009,

http://www.atmos-chem-phys-discuss.net/9/26969/2009/.

Pöschl, U.: Formation and decomposition of hazardous chemical components contained in atmospheric aerosol particles, Journal of Aerosol Medicine-Deposition Clearance and Effects in the Lung, 15, 203-212, 2002.

Pöschl, U.: Atmospheric aerosols: Composition, transformation, climate and health effects, Angewandte Chemie-International Edition, 44, 7520-7540, 2005.

Pöschl, U., Rudich, Y., and Ammann, M.: Kinetic model framework for aerosol and cloud surface chemistry and gas-particle interactions - Part 1: General equations, parameters, and terminology, Atmos. Chem. Phys., 7, 5989-6023, 2007, http://www.atmos-chem-phys.net/7/5989/2007/.

Rincon, A. G., Guzman, M. I., Hoffmann, M. R., and Colussi, A. J.: Optical absorptivity versus molecular composition of model organic aerosol matter, J. Phys. Chem. A., 113, 10512-10520, 2009.

Rogge, W. F., Hildemann, L. M., Mazurek, M. A., Cass, G. R., and Simonelt, B. R. T.: Sources of fine organic aerosol: 1. Charbroilers and meat cooking operations, Environ. Sci. Technol., 25, 1112-1125, 1991.

Rudich, Y.: Laboratory perspectives on the chemical transformations of organic matter in atmospheric particles, Chem. Rev., 103, 5097-5124, 2003.

Rudich, Y., Donahue, N. M., and Mentel, T. F.: Aging of organic aerosol: Bridging the gap between laboratory and field studies, Ann. Rev. Phys. Chem., 58, 321-352, 2007.

Sage, A. M., Weitkamp, E. A., Robinson, A. L., and Donahue, N. 
M.: Reactivity of oleic acid in organic particles: changes in oxidant uptake and reaction stoichiometry with particle oxidation, Phys. Chem. Chem. Phys., 11, 7951-62, 2009.

Schwartz, S. E. and Freiberg, J. E.: Mass-transport limitation to the rate of reaction of gases in liquid droplets - Application to oxidation of $\mathrm{SO}_{2}$ in aqueous-solutions, Atmos. Environ., 15, 11291144, 1981.

Seinfeld, J. H. and Pandis, S. N.: Atmospheric chemistry and physics - From air pollution to climate change, John Wiley \& Sons, Inc., New York, 1998.

Shiraiwa, M., Garland, R. M., and Pöschl, U.: Kinetic double-layer model of aerosol surface chemistry and gas-particle interactions (K2-SURF): Degradation of polycyclic aromatic hydrocarbons exposed to $\mathrm{O}_{3}, \mathrm{NO}_{2}, \mathrm{H}_{2} \mathrm{O}, \mathrm{OH}$ and $\mathrm{NO}_{3}$, Atmos. Chem. Phys., 9, 9571-9586, 2009,

http://www.atmos-chem-phys.net/9/9571/2009/.

Smith, G. D., Woods, E., DeForest, C. L., Baer, T., and Miller, R. E.: Reactive uptake of ozone by oleic acid aerosol particles: Application of single-particle mass spectrometry to heterogeneous reaction kinetics, J. Phys. Chem. A., 106, 8085-8095, 2002.

Smith, G. D., Woods, E., Baer, T., and Miller, R. E.: Aerosol uptake described by numerical solution of the diffusion - Reaction equations in the particle, J. Phys. Chem. A., 107, 9582-9587, 2003.

Springmann, M., Knopf, D. A., and Riemer, N.: Detailed heterogeneous chemistry in an urban plume box model: reversible co-adsorption of $\mathrm{O}_{3}, \mathrm{NO}_{2}$, and $\mathrm{H}_{2} \mathrm{O}$ on soot coated with benzo[a]pyrene, Atmos. Chem. Phys., 9, 7461-7479, 2009

Swallen, S. F., Kearns, K. L., Mapes, M. K., Kim, Y. S., McMahon, R. J., Ediger, M. D., Wu, T., Yu, L., and Satija, S.: Organic glasses with exceptional thermodynamic and kinetic stability, Science, 315, 353-356, 2007.

Thornberry, T. and Abbatt, J. P. D.: Heterogeneous reaction of ozone with liquid unsaturated fatty acids: detailed kinetics and gas-phase product studies, Phys. Chem. Chem. Phys., 6, 84-93, 2004.

Titov, V. N., Konovalova, G. G., Lisitsyn, D. M., Razumovskii, S. D., Nezhdanova, I. B., and Kukharchuk, V. V.: Kinetics of fatty acid oxidation in low density lipoproteins evaluated by registration of the oxidizer consumption and reaction product yield, Bulletin of Experimental Biology and Medicine, 140, 38-40, 2005.
Vesna, O., Sax, M., Kalberer, M., Gaschen, A., and Ammann, M.: Product study of oleic acid ozonolysis as function of humidity, Atmos. Environ., 43, 3662-3669, 2009.

Vieceli, J., Roeselova, M., Potter, N., Dang, L. X., Garrett, B. C., and Tobias, D. J.: Molecular dynamics simulations of atmospheric oxidants at the air-water interface: Solvation and accommodation of $\mathrm{OH}$ and $\mathrm{O}_{3}$, J. Phys. Chem. B., 109, 15876-15892, 2005.

Wiedensohler, A., Cheng, Y. F., Nowak, A., Wehner, B., Achtert, P., Berghof, M., Birmili, W., Wu, Z. J., Hu, M., Zhu, T., Takegawa, N., Kita, K., Kondo, Y., Lou, S. R., Hofzumahaus, A., Holland, F., Wahner, A., Gunthe, S. S., Rose, D., Su, H., and Pöschl, U.: Rapid aerosol particle growth and increase of cloud condensation nucleus activity by secondary aerosol formation and condensation: A case study for regional air pollution in northeastern China, J. Geophys. Res.-Atmos., 114, D00G08, doi:10.1029/2008jd010884, 2009.

Worsnop, D. R., Morris, J. W., Shi, Q., Davidovits, P., and Kolb, C. E.: A chemical kinetic model for reactive transformations of aerosol particles, Geophys. Res. Lett., 29, 20, doi:10.1029/2002GL015542, 2002.

Zahardis, J. and Petrucci, G. A.: The oleic acid-ozone heterogeneous reaction system: products, kinetics, secondary chemistry, and atmospheric implications of a model system - a review, Atmos. Chem. Phys., 7, 1237-1274, 2007, http://www.atmos-chem-phys.net/7/1237/2007/.

Ziemann, P. J.: Aerosol products, mechanisms, and kinetics of heterogeneous reactions of ozone with oleic acid in pure and mixed particles, Faraday Discuss., 130, 469-490, 2005.

Zobrist, B., Marcolli, C., Pedernera, D. A., and Koop, T.: Do atmospheric aerosols form glasses?, Atmos. Chem. Phys., 8, 52215244, 2008,

http://www.atmos-chem-phys.net/8/5221/2008/. 